\title{
La crítica de Aristóteles y Teofrasto a la concepción ígnea del ojo*
}

\author{
Javier Aguirre \\ Universidad del País Vasco-Euskal Herriko Unibertsitatea \\ javiaguirre05@hotmail.com \\ Aristotle's and Theophrastus' critique \\ to the igneous conception of the eye
}

\begin{abstract}
Aristóteles en De Sensu y Teofrasto en De Sensibus subrayan el hecho de que la mayoría de los que se han dedicado a estudiar la percepción visual desarrollan doctrinas que identifican la visión con el fuego. Ambos filósofos rechazan tales doctrinas, y particularmente la concepción ígnea del ojo en las que se basan. Aristóteles y Teofrasto analizan críticamente las doctrinas de Alcmeón, Empédocles y Platón, y frente a ellos Aristóteles defiende la naturaleza acuosa del ojo y una doctrina de la percepción visual centrada en el carácter diáfano del medio acuoso.
\end{abstract}

Palabras clave: Aristóteles; Teofrasto; presocráticos; Platón; ojo; visión; fisiología.
Aristotle in De Sensu and Theophrastus in De Sensibus underline the fact that most of those who devoted themselves to the study of the visual perception developed doctrines that tend to identify the capacity of vision with fire. Both philosophers reject such doctrines, and particularly the igneous conception of the eye on which they are based. Aristotle and Theophrastus analyze critically the doctrines of Alcmeon, Empedocle and Plato, and Aristotle claims the watery nature of the eye as well as a doctrine of the visual perception centred on the diaphanous character of the watery way.

Key words: Aristotle; Theophrastus; the Presocratics; Plato; eye; sight; physiology.

Al comienzo del capítulo segundo de Sobre la sensación (= De Sensu), breve tratado perteneciente a la colección Parua Naturalia, Aristóteles afirma

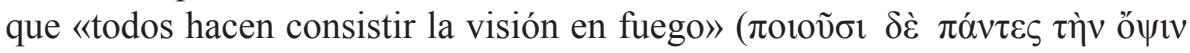
$\pi \nu \rho o ́ \varsigma)^{1}$. Por su parte, en el tratado Sobre las sensaciones (= De Sensibus),

* Trabajo que se enmarca dentro del proyecto de investigación $\mathrm{I}+\mathrm{D}+\mathrm{i}$ del Ministerio de Ciencia e Innovación con referencia FFI2009-11795, titulado «La tradición gnoseológica aristotélica y los orígenes de la filosofía de la mente».

${ }^{1}$ De Sensu 2, 437 23. Para todas las referencias a De Sensu utilizo la edición griega de Mugnier 1965 y la traducción anotada de Bernabé 1987. 
Teofrasto afirma que «la mayoría considera que la vista es de fuego» ( $\tau_{\imath} \theta \varepsilon \dot{\varepsilon} \alpha \sigma \iota$

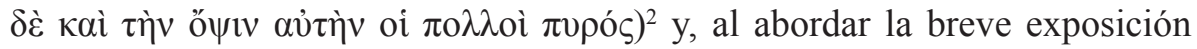
de la doctrina de la visión atribuida a Clidemo, afirma de este oscuro pensa-

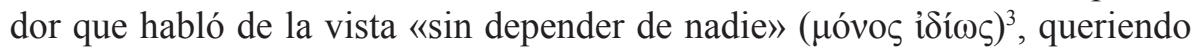
expresar con ello que Clidemo explicó la visión recurriendo a la naturaleza transparente de los ojos y no a su naturaleza ígnea. Las afirmaciones de Aristóteles y Teofrasto al respecto pueden resultar exageradas si se tiene en cuenta que otros importantes fisiólogos de la percepción por ellos mismos analizados en ambos tratados, como es el caso de Anaxágoras, Demócrito y Diógenes de Apolonia, rechazan de un modo u otro la naturaleza ígnea del ojo. Y sin embargo, la precaución de Aristóteles y Teofrasto es plenamente entendible, habida cuenta de que a la concepción ígnea de la visión se adhieren pensadores de gran reputación que parecen basar sus doctrinas en la observación de cotidianos fenómenos naturales. Dentro de este grupo son analizadas críticamente las doctrinas de Alcmeón de Crotona, Empédocles y Platón. Frente a ellos, Aristóteles y Teofrasto desarrollan una concepción de la naturaleza del ojo que subraya la importancia de la presencia del agua en su estructura y configuración, así como una doctrina de la percepción visual centrada en el carácter diáfano del medio acuoso. El hecho de que Aristóteles centre sus críticas particularmente en la naturaleza ígnea del ojo se debe, precisamente, a su propia concepción general de la percepción, según la cual en toda percepción siempre se necesita un medio, y más concretamente un medio diáfano, característica que comparten al aire y al agua, pero no el fuego. A lo largo de las siguientes páginas trataré la exposición y el análisis crítico realizado por Aristóteles y Teofrasto ${ }^{4}$ a las doctrinas de la percepción visual

2 De Sensibus 37. Para todas las referencias a De Sensibus utilizo la edición griega y traducción anotada de Solana 2006; también tengo siempre presente la edición crítica de Diels 1879, así como la traducción italiana de Torraca 1961.

${ }^{3}$ De Sensibus 38. Las noticias sobre Clidemo se encuentran recogidas en DK 62.

${ }^{4}$ El tratamiento conjunto de ambos autores en el estudio de la percepción sensible está justificado por el modo en que Teofrasto sigue el método de exposición y análisis crítico llevado a cabo por Aristóteles, breve y brillantemente descrito por Kahn 1960, p. 18: «The expository section is in general much fuller than Aristotle's own mention of his predecessors' views, and there is in many cases no Aristotelian reference whatsoever to the doctrine reported by Theophrastus. The case of his critical judgement is similar. Sometimes the objections presuppose an Aristotelian point of view, but more often they are aimed at internal inconsistencies or incompleteness in the doctrines described». En la misma línea interpretativa, Baltussen 2000, pp. 93-94, subraya dos características fundamentales en el modo en que Teofrasto 
desarrolladas por estos tres filósofos, y particularmente a la concepción ígnea del ojo como aspecto fundamental de aquellas.

De la breve y escueta exposición que Teofrasto y Aristóteles dedican a la doctrina óptica de Alcmeón, parece deducirse que el filósofo de Crotona atribuye cierta importancia a la presencia del fuego en la constitución y funcionamiento del ojo. En su exposición, Teofrasto ${ }^{5}$ afirma que, a juicio del filósofo de Crotona, los ojos «ven con lo brillante y lo transparente» (ó $\rho \tilde{\alpha} v$

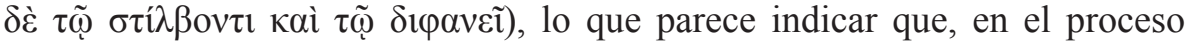
de la visión, el funcionamiento del ojo es posible gracias a la presencia activa del fuego (brillante) y del agua (transparente) ${ }^{6}$, y añade seguidamente que la visión se produce «cuando (lo transparente) refleja la imagen» (ő $\tau \alpha v$

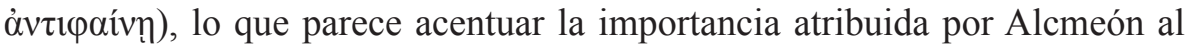
agua frente al fuego en la constitución y funcionamiento del ojo. En la descripción de Teofrasto, lo más interesante es, sin embargo, la atención prestada a un conocido fenómeno óptico cuya observación atribuye a Alcmeón y según

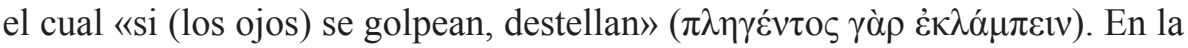
exposición crítica de las teorías de los sensorios desplegada por Aristóteles

sigue a Aristóteles en su exposición y evaluación de las doctrinas sobre la percepción: a) Teofrasto parte generalmente de Aristóteles y trata de clarificar aspectos concretos tratados por el Estagirita que admiten una múltiple clarificación. Al mismo tiempo, Teofrasto muestra su independencia al plantear cuestiones no presentes en la exposición aristotélica y destinadas a aclarar aspectos de su propio interés. $b$ ) Existe un acuerdo total de Teofrasto con la exposición y la evaluación aristotélicas de las doctrinas de los pensadores anteriores. Por lo general, estas doctrinas nunca son explicadas nuevamente por Teofrasto. Podemos afirmar, por consiguiente, que Teofrasto asume como punto de partida la exposición y la evaluación de Aristóteles, si bien las enriquece con sus propias aportaciones. Sobre el estado de la cuestión de la originalidad de Teofrasto con respecto a Aristóteles, puede consultarse el segundo apartado del capítulo «Teofrasto, más allá de Aristóteles», en Solana 2006, pp. 11-22.

${ }^{5}$ Cf. De Sensibus 26. La doctrina de Alcmeón sobre las sensaciones es tratada por Teofrasto en los capítulos 25 y 26. Todas nuestras referencias pertenecen al capítulo 26, por ser este el capítulo en el que Teofrasto se ocupa de la visión.

${ }^{6}$ Sigo la interpretación mayoritaria de Watchler 1896, p. 49; Stratton 1917, p. 176 n. 79; Sassi 1978, pp. 78-79, y Solana 2006, p. 84 n. 55, según la cual cada uno de los dos adjetivos se refieren, respectivamente, al fuego y al agua, y no solamente al agua, tal como propone Beare 1906, p. 12. 
en De Sensu 2, el Estagirita ${ }^{7}$ ya había analizado extensamente este fenómeno visual. Según la descripción aristotélica, tanto bajo la oscuridad como con los párpados cerrados - situación en que también se produce oscuridad-, si se aprieta un ojo y se le mueve, «parece brillar un fuego» ( $\left.\dot{\varepsilon} \kappa \lambda \alpha_{\alpha} \mu \pi \varepsilon v\right)^{8}$. El interés de la descripción del fenómeno radica en que Aristóteles atribuye al desconocimiento de la causa de este fenómeno la razón de que todos identifiquen la naturaleza del ojo con el fuego ${ }^{9}$. La descripción de una dificultad asociada a dicha identificación y la ulterior explicación del fenómeno constituyen, precisamente, el primer paso de Aristóteles para rechazar la concepción ígnea del ojo antes de continuar la exposición y crítica de las restantes doctrinas sobre la visión y exponer su propia doctrina al respecto. En primer lugar, el Estagirita plantea la dificultad de que, en el caso de que el ojo estuviera constituido por fuego, sería forzoso que el ojo se viera siempre a sí mismo y que el sujeto fuera consciente de ello, y no solo cuando el ojo es apretado y movido, sino también cuando está inmóvil ${ }^{10}$. Inmediatamente después, Aristóteles explica la causa del fenómeno remitiéndose a otro fenómeno, según el cual los objetos lisos brillan en la oscuridad aunque ellos mismos no produzcan luz ${ }^{11}$. En relación al ojo, resulta que el iris del ojo es liso, por lo que, en consecuencia, el iris brilla en la oscuridad ${ }^{12}$. Sin embargo, el fenómeno del brillo del ojo, únicamente se produce cuando el ojo es movido, lo que a juicio del filósofo es debido a que, a causa del movimiento, parece como si un solo objeto se transformara en dos. Aristóteles tiene en mente el conocido fenómeno óptico según el cual un objeto sujeto a un rápido movimiento produce la ilusión de la presencia de dos objetos distintos, lo que a su vez es debido a la persistencia de la visión ${ }^{13}$. Así pues, según la explicación

${ }^{7}$ Cf. De Sensu 2, 437ª $23-437^{\mathrm{b}} 10$.

${ }^{8}$ De Sensu 2, 437 24.

${ }^{9}$ Cf. De Sensu 2, $437^{\mathrm{a}} 23$ y $30-31$.

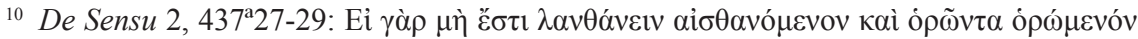

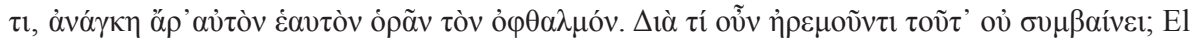
argumento de Aristóteles parece evidente: si el ojo está en funcionamiento y su composición es ígnea, entonces debe verse siempre a sí mismo, y no solo cuando es presionado y movido.

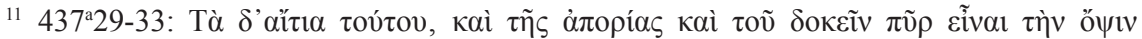

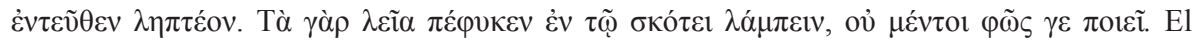
fenómeno ha sido descrito por el filósofo en de An. II 7, 419ª1-6.

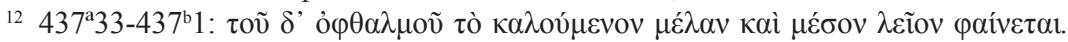

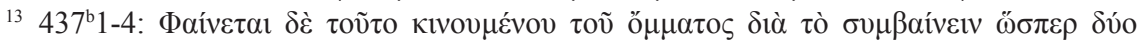

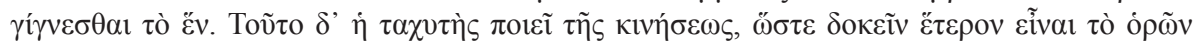


de Aristóteles, el iris del ojo es un cuerpo que por su naturaleza lisa brilla en la oscuridad, y tal brillo es captado por el ojo cuando es movido velozmente, pues con el movimiento lo que de por sí constituye un solo objeto -el ojo y su propio brillo - se desdobla, de modo que el primero se pone frente al segundo. Expresado brevemente: el ojo se ve a sí mismo, igual que en la re-

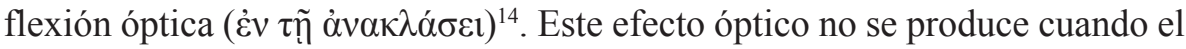
ojo se mueve lentamente, pues en tal caso la vista no persiste suficientemente como para que el ojo y su brillo aparezcan como dos realidades distintas.

Por lo demás, a excepción de la atención prestada por Aristóteles al fenómeno analizado, la doctrina de Alcmeón no parece presentar mayor interés a los ojos de Aristóteles y Teofrasto; en efecto, tal como ya se ha señalado, la importancia otorgada por Alcmeón a la presencia del fuego en la constitución del ojo $\mathrm{y}$, en general, en la visión es menor que la concedida al agua y a su naturaleza transparente ${ }^{15}$, de modo que su doctrina sobre la percepción visual cabría considerarla incluso como un anticipo de la propia doctrina aristotélica de la percepción visual ${ }^{16}$. En este sentido, la atención de Aristóteles y Teofrasto se dirige con mucho mayor interés hacia las doctrinas de Empédocles y Platón, por ser estos los autores que de una manera más clara explican la constitución del ojo y el proceso de la percepción visual recurriendo a la presencia del fuego.

\section{II}

En De Sensu 2, Aristóteles ${ }^{17}$ plantea dos críticas a la doctrina de Empédocles: en primer lugar, si, tal como afirma el filósofo de Agrigento, la vista es fuego y la visión se produce por medio de una luz que sale del ojo y que actúa como

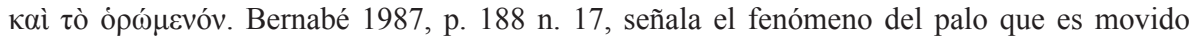
rápidamente entre los dedos.

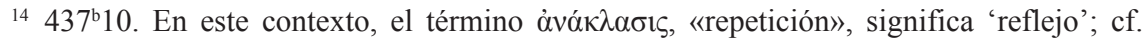
Beare 1906, pp. 82-83. Alejandro de Afrodisias $(19,20)$ explica el fenómeno diciendo que el ojo ve una parte de sí mismo como siendo otro: ópã

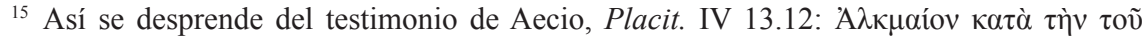

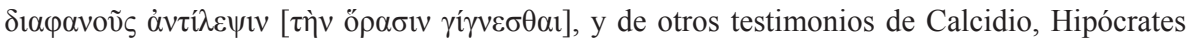
y Aristóteles reunidos en DK 24A10.

${ }^{16}$ La importancia concedida por Aristóteles a la naturaleza acuosa y transparente o diáfana del ojo está expresada en De An. II 7, $418^{\mathrm{b}} 4$ ss. y De Sensu $2,438^{\mathrm{a}} 6$ ss. y $438^{\mathrm{b}} 6$ ss.

${ }^{17}$ La exposición crítica de la doctrina de Empédocles se encuentra en De Sensu 2, 437b 10 14 y $437^{\mathrm{b}} 23-438^{\mathrm{a}} 5$. 
si fuera una linterna, se plantea la dificultad de «por qué la vista no puede

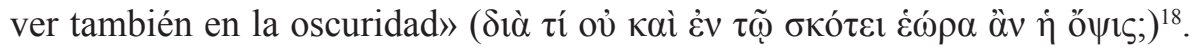
Como veremos más adelante, esta crítica también está dirigida a la doctrina de la percepción visual expuesta por Platón en el Timeo ${ }^{19}$. En segundo lugar, el Estagirita se hace eco de una supuesta contradicción en la que cae Empédocles, por la razón de que este parece creer en ocasiones que la vista se produce gracias a la luz que procede del ojo, mientras que en otras ocasiones atribuye la visión a las emanaciones producidas por los objetos que se ven. Con respecto a la primera crítica, lo afirmado por Aristóteles está confirmado por un fragmento de Empédocles que el propio Aristóteles reproduce inmediatamente después. El fragmento afirma lo siguiente ${ }^{20}$ :

Como cuando alguien que piensa ponerse en camino se provee de una lámpara, resplandor de ardiente fuego en noche borrascosa, tras haberle acoplado linternas, a prueba de los vientos más varios, que dispersan el soplo de los vientos que sobre ella se abaten, mientras que la luz salta fuera de ellas, en tanto que es más fina, y refulge por el umbral con indomables rayos, así también antaño, encerrado en las membranas, el fuego primigenio dio origen a la redonda niña, con delicados tejidos, que se hallan de parte a parte atravesados por maravillosos conductos. Éstos la protegen de la profundidad del agua que corre en redor suyo, pero el fuego pasa a su través, en tanto que es más fino.

Como es habitual en su modo de expresión, Empédocles hace uso de un lenguaje poético repleto de imágenes y metáforas, que en esta ocasión utiliza para describir la naturaleza fundamentalmente ígnea del ojo (versos 1, 2, 3 y 7), su estructura compartimentada que permite separar el fuego del agua (versos 7,8 y 9) y explicar la percepción visual como luz que, procedente del ojo, se dirige al exterior a través de canales (versos 5, 6 y 10). Asimismo, del fragmento completo parece desprenderse que en la concepción empedoclea de la anatomía del ojo están presentes el fuego, el agua, la tierra y el aire.

${ }^{18}$ De Sensu 2, 437ª 13-14.

${ }_{19}$ Cf. Pl., Ti. 45 b ss. y 67 e ss.

${ }^{20}$ Emp. B 84 DK. Traducción de Bernabé 1987, pp. 189-190. 
La segunda dificultad planteada por Aristóteles, relativa a la supuesta contradicción en la que habría incurrido Empédocles al plantear al mismo tiempo la doctrina de las emanaciones o efluvios procedentes de los objetos y la doctrina de la luz proveniente del ojo a modo de linterna, ha provocado numerosos comentarios ${ }^{21}$. El problema de la supuesta incompatibilidad de ambas doctrinas puede solventarse, sin embargo, aceptando que para Empédocles la visión se produce, efectivamente, cuando las emanaciones de los objetos visibles entran por el ojo, pero aceptando a su vez que la luz del interior del ojo resulta complementaria con la luz exterior a fin de que la visión se haga posible. En todo caso, esta solución resulta parcial, habida cuenta de que posteriormente habría que dilucidar en qué consiste o de qué modo se materializa esa colaboración entre las emanaciones y la luz ígnea del ojo en la formación de la imagen visual ${ }^{22}$.

La exposición de Teofrasto ${ }^{23}$ parte de la de Aristóteles. Como es habitual, Teofrasto añade importantes precisiones, algunas de las cuales no hacen sino aclarar el propio contenido de B 84, fragmento recogido por el Estagirita,

${ }^{21}$ Las dos versiones han sido discutidas, entre otros, por Beare 1906, pp. 17-18; Verdenius 1948, pp. 160-162; Long 1966, pp. 262-264; O’Brien 1970, pp. 140-146, y Sassi 1978, pp. 85-88.

${ }^{22}$ Con respecto a esta cuestión, Beare 1906, p. 15, ha descrito las tres alternativas posibles: a) que la luz ígnea del ojo atraviese simplemente la capa de agua hasta la superficie del ojo; b) que la luz salga del ojo y se dirija hasta el objeto visible; $c$ ) que las emanaciones del objeto y la luz del ojo se encuentren en un punto intermedio. La alternetiva $c$ se identifica con la

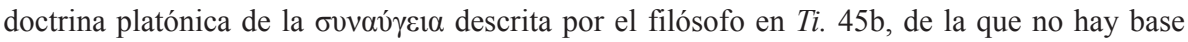
documental para adscribírsela a Empédocles. La opción más acorde con las descripciones de Aristóteles y Teofrasto y del propio Empédocles parece ser la $b$, solución desarrollada por Wright 1981, p. 242: «There is no incompatibility here. From Plato and Theophrastus it is clear that for E[mpedocles] vision occurs when the effluences fit into the pores of the eye (cf. Meno 76c, Sens. 7), and there is no question of a coalescence of fire from eye and light from the object, as in Plato Tim. 45b, Theaet. 156d. But light from fire within the eye is as necessary for vision as external light, and the two are complementary (for eyes with less fire see better by day, and those with more, by night)». Hay que subrayar, finalmente, que en su exposición crítica de la doctrina visual empedoclea Teofrasto no se hace eco de contradicción alguna; ya en el primer capítulo de De Sensibus, el Licearca atribuye a Empédocles la idea general de que «el sentir acontece por causa del efluvio» (

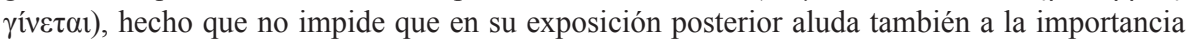
que en la visión posee la luz ígnea proveniente del ojo.

${ }^{23}$ La exposición de la doctrina empedoclea de la percepción visual está desarrollada en De Sensibus 7 y 8, y la crítica en los capítulos 17-20. 
mientras que otras proceden de diversos testimonios aristotélicos y de otras fuentes desconocidas. Su exposición crítica es, por otro lado, mucho más sistemática que la de Aristóteles. En lo que respecta a la descripción empedoclea del ojo, expuesta en De Sensibus 7, Teofrasto precisa que junto a la presencia fundamental del fuego también se encuentran los otros tres elementos. Según la exposición de Teofrasto, el interior del ojo se compone de fuego, rodeado de tierra ${ }^{24} \mathrm{y}$ aire ${ }^{25}$, a través de los cuales aquel, por ser más

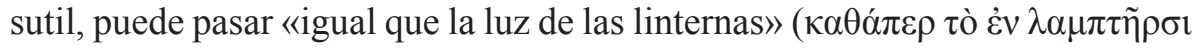
$\varphi \tilde{\omega} \varsigma)$, imagen empedoclea de la que dan cuenta tanto Teofrasto como Aristóteles. Asimismo, Teofrasto añade en su exposición que en la estructura externa o membrana del ojo se distinguen poros de fuego y de agua dispuestos alternadamente, y precisa que por medio de los poros de fuego conocemos los objetos blancos, mientras que por medio de los de agua conocemos los objetos negros, «pues cada tipo de objetos se adapta a sus poros respectivos»

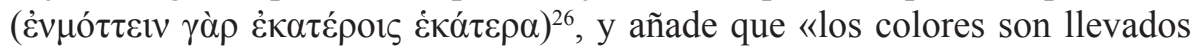

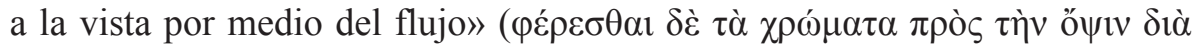

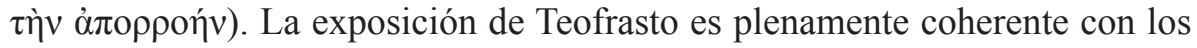
principios generales que sobre la percepción defiende el filósofo de Agrigento, según los cuales «el sentir acontece por medio del efluvio, al tiempo que

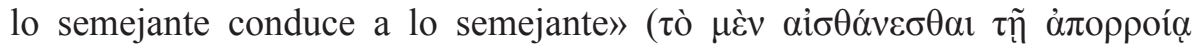

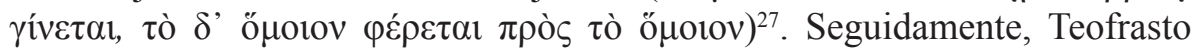

${ }^{24}$ Si hacemos caso de B 85, en comparación con el fuego y el agua la presencia de la tierra en la constitución del ojo y en el proceso de la percepción visual es desdeñable: $\dot{\eta} \delta \dot{\varepsilon}$

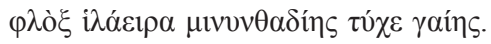

${ }_{25}$ Con respecto a esta cuestión, en las dos obras de Diels se dan versiones distintas: en

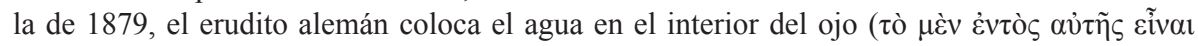

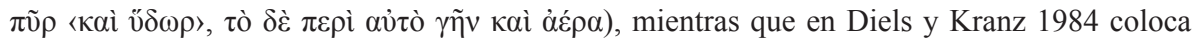

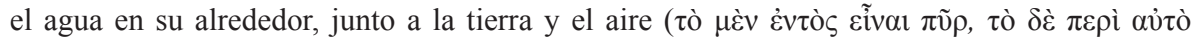

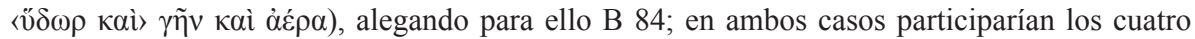
elementos en la descripción empedoclea de la configuración del ojo, tal como parece exigir B

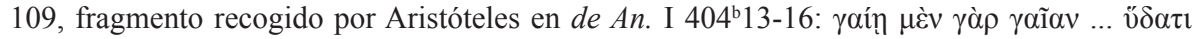

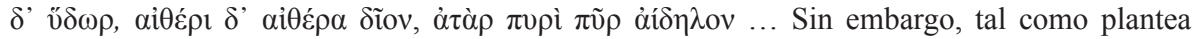
Stratton 1917, p. 64 n. 25, siguiendo una sugerencia manuscrita de Taylor, el aire del que habla Teofrasto no significa el aire atmosférico, sino el aire-humedad, de modo que la introducción del agua en el pasaje de Teofrasto por parte de Diels no estaría justificado.

${ }^{26}$ La relación que Empédocles establece entre la constitución ígnea y acuosa del ojo y la percepción de blanco y el negro está expuesta por Aristóteles en $G A \mathrm{~V} 1,779^{\mathrm{b}} 15$ ss.

${ }^{27}$ De Sensibus 1. 
aporta en De Sensibus 8 importantes datos que no se encuentran en la descripción aristotélica. Según la exposición de Teofrasto, los ojos no tienen la misma composición de fuego y agua ${ }^{28} \mathrm{ni}$ el fuego se encuentra en la misma posición, sino que en unos se encuentra en el centro del ojo y en otros alejado de él, característica a la que Empédocles atribuye, según Teofrasto, el hecho de que unos animales vean de modo más penetrante de día y que otros lo hagan de noche. Los animales cuyos ojos tienen menos fuego ven mejor de día debido a que en ellos la luz interior es igualada por la exterior, mientras que los que tienen ojos con menos agua ven mejor de noche debido a que en ellos tal defíciencia también queda compensada por el aire húmedo de la noche. Paralelamente, los animales cuyos ojos tienen más fuego ven peor de día y los que poseen más agua ven peor de noche. La explicación de Empédocles recogida por Teofrasto afirma que los ojos que tienen abundante fuego ven peor de día porque entonces, al ser más abundante el fuego, este cierra y ocupa los poros del agua; por el contrario, los ojos que tienen abundante agua ven peor de noche porque entonces el agua cierra y ocupa los poros del fuego. La situación se compensa una vez que en unos el agua es separada por la luz exterior y en otros el fuego es separado por el aire. Teofrasto concluye que, según la doctrina empedoclea, los ojos que mejor ven son aquellos cuyos dos elementos constituyentes principales, el fuego y el agua, están combinados en la misma proporción ${ }^{29}$.

A lo largo de De Sensibus 17-20, Teofrasto despliega de modo perspicaz una extensa crítica a la doctrina de los efluvios y a la concepción ígnea del ojo expuesta por Empédocles. A lo largo de esos capítulos, Teofrasto plantea cinco críticas dirigidas a diversos aspectos de la doctrina empedoclea previamente expuesta en De Sensibus 7-8. En primer lugar, a juicio del Licearca,

28 Para la interpretación de esta parte de la exposición, sigo la enmienda del texto griego

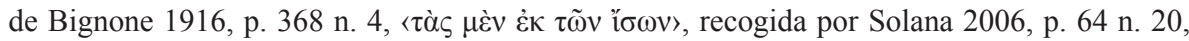

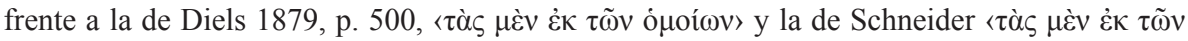
$\alpha \cup ่ \tilde{\omega} v>$.

29 Sassi 1978, p. 89, llama la atención sobre la importancia que el aspecto relativo y subjetivo de la percepción visual adquiere en Empédocles; en efecto, la capacidad perceptiva visual depende de las dos variables señaladas por Empédocles: 1) la posición del fuego dentro del ojo - variable que simplemente recoge pero sin extenderse en ella- y 2) la proporción cuantitativa entre agua y fuego en la constitución del ojo. A este respecto, cf. el testimonio aristotélico de $G A$ V 1, $779^{\mathrm{b}} 15$ ss. (= 31A91). Sobre la posibilidad de identificar ambas variables, cf. Stratton 1917, pp. 164-165 n. 30. 
Empédocles no explica de modo coherente las sensaciones consideradas des-

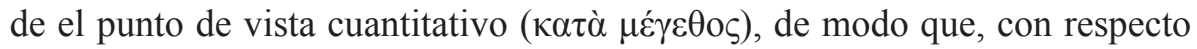
a la percepción visual, deja sin explicación la forma en que el sujeto llega a conocer el color gris y el resto de los colores compuestos. Efectivamente, si, tal como plantea el filósofo de Agrigento, el ojo, al componerse de agua y fuego, puede conocer el negro y el blanco por los semejantes, ¿cómo podría conocer también el gris y el resto de colores compuestos? Porque, de hecho, tales colores son vistos del mismo modo que lo son el blanco y el negro. A juicio de Teofrasto, el conocimiento de aquellos no puede ser explicado por medio de la doctrina de los poros. En segundo lugar, Teofrasto rebate la afirmación empedoclea según la cual hay animales que ven mejor de día y otros lo hacen mejor de noche; a esta afirmación Teofrasto opone que el fuego menor es destruido por el fuego mayor, de modo que no es posible mirar directamente al sol y al fuego puro. Y añade que, si lo semejante aumenta la visión y lo desemejante la obstaculiza, entonces todos deberíamos ver mejor los objetos blancos de día y los oscuros de noche, cuando la experiencia nos enseña que casi todos ven mejor de día, y las excepciones a la norma general se deben a que el propio fuego interior de algunos animales refuerza la capacidad para ver de noche ${ }^{30}$. En tercer lugar, Teofrasto critica la vinculación establecida por Empédocles entre composición de fuego y agua en el ojo, por un lado, y capacidad visual, por otro. En efecto, a juicio de Teofrasto, aquellos que poseen una mezcla formada por partes iguales de fuego y agua, necesariamente aumentarán y disminuirán alternativamente cada uno de esos componentes $^{31}$, de modo que si, tal como afirma Empédocles, el exceso de un componente impide la acción del otro, entonces la disposición de todos será aproximadamente igual. En cuarto lugar, Teofrasto despliega su crítica a la concepción general según la cual lo semejante se conoce por medio de lo

${ }^{30}$ De este modo, Teofrasto explica la visión nocturna exactamente del modo contrario a como lo hace Empédocles, pues mientras este la atribuye a la deficiencia de agua en el ojo - deficiencia compensada por el aire húmedo de la noche-, Teofrasto lo atribuye a la presencia de fuego, que aporta luz y facilita la visión nocturna. Detrás de la crítica de Teofrasto está, tal como se observa más adelante, su rechazo a explicar la percepción en términos de semejanza.

${ }^{31}$ Es de suponer que Teofrasto quiere indicar que, si se acepta lo afirmado en el capítulo 8, el ojo aumentará su composición de fuego durante el día a causa de la luz exterior, y su composición de agua durante la noche a causa de la humedad exterior, de modo que finalmente no habrá ningún ojo especialmente preparado para la visión. 
semejante; a este respecto, Teofrasto observa que ni el sonido se percibe mediante el sonido ni el olor mediante el olor; muy al contrario, parece que todos los sentidos se hacen tanto más débiles cuanto más llenos están de elementos semejantes, de tal modo que, para que la percepción sea posible, es necesario que el órgano de la sensación esté libre de toda afección. Según la concepción de Teofrasto, la percepción sensible en todas sus formas, lejos de producirse por medio de semejantes, se produce por sus contrarios. Y finalmente, Teofrasto se opone a la doctrina de las emanaciones, alegando que, de hecho, de los cuatro elementos establecidos por Empédocles, solo del fuego parece haber emanaciones, pero no de los otros tres elementos.

Podemos comprobar que Aristóteles y Teofrasto, aun coincidiendo en la exposición general de la doctrina empedoclea de la composición del ojo y de la naturaleza de la visión, centran principalmente sus críticas en dos aspectos distintos: Aristóteles dirige su crítica a la importancia atribuida por Empédocles al papel del fuego dentro de la estructura del ojo, a la naturaleza ígnea del ojo, pues su mayor interés se centra en subrayar la naturaleza acuosa del ojo y su carácter diáfano capaz de permitir la recepción de la luz ${ }^{32}$. Teofrasto, por su parte, aun sin obviar esta cuestión, dirige principalmente su crítica a la doctrina de las emanaciones y al principio del similia similibus, que para el Licearca supondría la manifestación más clara de un materialismo ingenuo defendido por Empédocles ${ }^{33}$.

La concepción ígnea del ojo, finalmente, tiene su expresión más madura en la obra de Platón, quien en el Timeo reúne la mayor parte de las escasas páginas que a lo largo de su obra dedica a los procesos fisiológicos relacionados con la percepción. Las críticas de Aristóteles y Teofrasto a la doctrina platónica de la percepción visual se dirigirán nuevamente a su concepción ígnea del ojo y a su doctrina de los efluvios o emanaciones.

La concepción platónica de la percepción visual es expuesta brevemente por el filósofo ateniense en dos pasajes del Timeo $^{34}$ donde queda patente el prota-

\footnotetext{
${ }^{32}$ La concepción acuosa del ojo está descrita por Aristóteles en De Sensu 2, 438b2-16.

${ }^{33}$ A este respecto, cf. Sassi 1978, pp. 84-86 y 91.

${ }^{34}$ La doctrina platónica de la percepción visual está expuesta en Ti. 45b ss. y 67 e ss.. Utilizo la edición griega de Albert Rivaud (1985), publicada en Les Belles Lettres, y la
} 
gonismo otorgado al fuego ${ }^{35}$. En su breve descripción, Platón afirma que, con el fin de construir los ojos humanos, los dioses «idearon un cuerpo de aquel

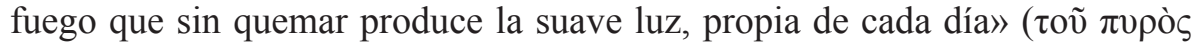

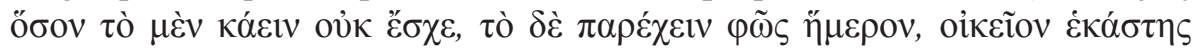

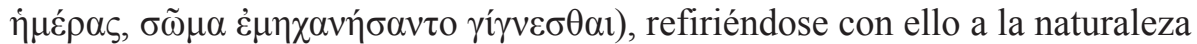
común del ojo y de la luz solar, y añade que posteriormente hicieron que ese fuego interior puro, de la misma naturaleza que aquel, «fluyera a través de

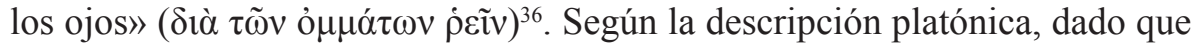
«lo semejante cae sobre lo semejante» ( durante el día la luz diurna se combina con el flujo visual, formando de ese modo un único cuerpo afín que, en forma de rayo, se dirige hacia el objeto de la visión ${ }^{37}$. Asimismo, cuando el conjunto formado por el fuego procedente del ojo y la luz del día entra en contacto con el fuego procedente del objeto, entonces se produce un movimiento que a través del cuerpo llega hasta el alma y produce la percepción ${ }^{38}$. Inmediatamente después, Platón expone las razones por las que el flujo visual se apaga durante la oscuridad y, como consecuencia, la visión desaparece ${ }^{39}$. El segundo fragmento corresponde al pasaje 67e-68d; en este pasaje Platón trata inicialmente sobre las propiedades de lo blanco y lo negro, de quienes afirma que el primero tiene la capacidad de dilatar el rayo visual, mientras que el segundo posee la propiedad contraria, y describe asimismo el proceso mediante el cual ambos son percibidos ${ }^{40}$;

traducción castellana de Gredos a cargo de Francisco Lisi (1992). Tanto la crítica de Aristóteles como la de Teofrasto parecen tener únicamente en cuenta lo expuesto por Platón en ese diálogo.

${ }^{35}$ De hecho, previamente, Platón afirma en Ti. $31 \mathrm{~b}$ que «nunca podría haber nada visible

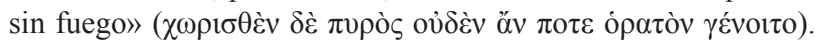

36 Timeo 45b.

$37 \mathrm{Cf}$. Timeo $45 \mathrm{c}$.

${ }^{38}$ Cf. Timeo $45 \mathrm{c}-\mathrm{d}$. De la propia descripción platónica se desprende que el proceso de

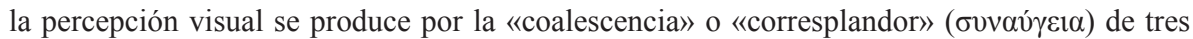
fuegos distintos: 1) el que desde el interior del ojo se dirige en forma de luz hacia el objeto de la visión; 2) el de la luz del día que se encuentra en el aire y que unido al anterior se dirige hacia el objeto de la visión; 3) el que emana del objeto de la visión y se dirige hacia la corriente ígnea formada por los dos fuegos anteriores. Cf. a este respecto el breve fragmento de Estobeo (= Diels 1879, 404). Platón ilustra en 46a-b el proceso de la coalescencia mediante la descripción de la formación de la imagen propia en el espejo.

${ }^{39}$ Cf. Ti. 45 d.

${ }^{40}$ Cf. Ti. 67e-68a. 
posteriormente, el filósofo describe detalladamente la mezcla de los nueve colores fundamentales ${ }^{41}$.

La breve crítica de Aristóteles ${ }^{42}$ a la explicación platónica de la visión expuesta en el Timeo se desentiende totalmente de la descripción del proceso perceptivo para centrarse en la cuestión de cómo es posible que la visión desaparezca en la oscuridad, habida cuenta de que, según la propia concepción platónica de la visión, la explicación de la percepción visual se basa en la naturaleza ígnea del ojo y en el fenómeno de los rayos de luz que desde el ojo salen al exterior. Aristóteles rechaza la afirmación platónica de que la luz que sale del ojo pueda apagarse durante la noche, y para ello expone una serie de dificultades que están asociadas a la tesis platónica: en primer lugar, según Aristóteles, debe tenerse en cuenta que lo húmedo y lo frío - cualidades relacionadas con la noche - son causas de la extinción de lo caliente y seco, que a su vez son cualidades que pueden ser atribuidas al fuego, pero que no parecen sin embargo ser atributos de la luz. Pero incluso en el caso de que lo caliente y lo seco pudieran también atribuírsele a la luz, continúa el Estagirita, entonces esta debería apagarse de día cuando llueve. Aristóteles argumenta, finalmente, que en el agua helada debería prevalecer la oscuridad, del mismo modo que la llama y los objetos en ignición se apagan en su presencia. Y sin embargo, concluye Aristóteles, ninguna de las consecuencias que con respecto a la luz se seguirían de la doctrina platónica de la visión se cumple realmente en la naturaleza. Podemos comprobar que son tres las ideas de partida en torno a las cuales se estructura la crítica de Aristóteles a Platón: 1) lo húmedo y lo frío interrumpen lo cálido y lo seco (= lo desemejante interrumpe lo desemejante); 2) lo húmedo y lo frío corresponden al aire nocturno y lo cálido y lo seco corresponden al fuego; 3 ) lo cálido y lo seco no corresponden a la luz. La crítica del Estagirita responde exactamente a la explicación de la interrupción nocturna de la visión expresada por Platón en Ti. 45d, donde afirma que al llegar la noche la visión se interrumpe porque «el fuego [de la luz diurna] que le es afín [al flujo del ojo] se marcha» (

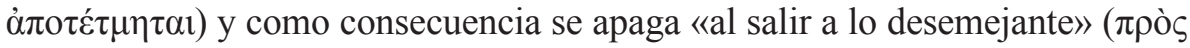

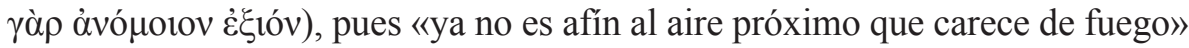

${ }^{41}$ Cf. Ti. 68b-d. Un excelente estudio de las mezclas de colores descritas por Platón en el Timeo se encuentra en Struycken 2003. También son muy valiosos los trabajos de Platnauer 1921 y de Osborne 1968.

${ }^{42}$ Expuesta en De Sensu 2, 437 $11-23$. 


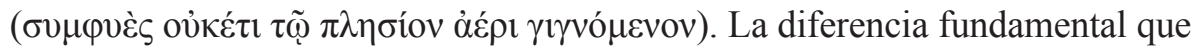
separa la explicación platónica y la crítica aristotélica la constituye la distinta concepción que ambos tienen de la naturaleza de la luz: Aristóteles, en efecto, rechaza la identificación platónica de la luz como fuego. Teofrasto ${ }^{43}$, por su parte, dedica a la exposición de la doctrina platónica de la percepción visual únicamente el capítulo 5 de De Sensibus. A propósito de la concepción ígnea del ojo, Teofrasto simplemente afirma que Platón «considera la visión de fue-

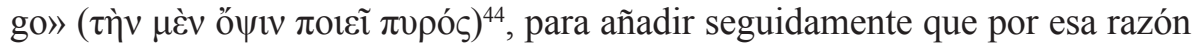
«el color es una llama que procede de los cuerpos, la cual tiene partes propor-

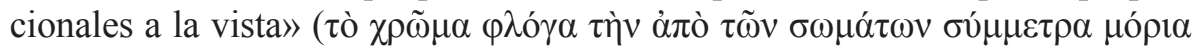

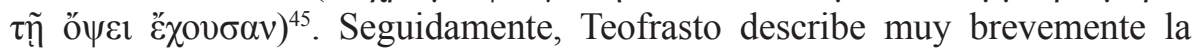

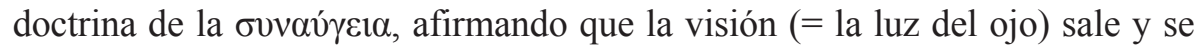
funde con el efluvio de los cuerpos, de modo que se produce la visión ${ }^{46}$. Finalmente, Teofrasto sitúa a Platón entre quienes sostienen que es la vista la que choca con los cuerpos y los que afirman que son los cuerpos los que envían determinadas partículas hacia la vista ${ }^{47}$.

En lo que respecta a la valoración crítica, Teofrasto la lleva a cabo de modo muy escueto en el capítulo final de su obra. La crítica tiene exclusivamente por objeto la doctrina de los colores, sobre la que afirma que «se ex-

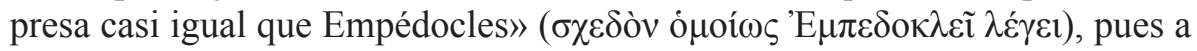

${ }^{43}$ Un excelente estudio de los pasajes que Teofrasto le dedica a Platón se encuentra en el capítulo «El informe sobre Platón y la fiabilidad del De Sensibus», en Solana 2006, pp. 23-36. Frente a la valoración negativa de McDiarmid 1959, que encuentra en la exposición y crítica de las doctrinas analizadas en De Sensibus manipulaciones y tergiversaciones, Solana demuestra claramente que el tratamiento de Teofrasto es de una gran objetividad.

${ }^{44}$ Con esta simple frase Teofrasto resume toda la exposición que al respecto Platón realiza en Ti. 45b. Además del ya citado capítulo de Solana 2006, la correlación entre los contenidos del Timeo y De Sensibus 5 ha sido esquemáticamente establecido por Stratton 1917, pp. 160-61 n. 15.

${ }^{45}$ Frase que reproduce fielmente el contenido de Ti. 67c y que Teofrasto repite casi literalmente al comienzo de De Sensibus 86: «El color es una llama procedente de los cuerpos que

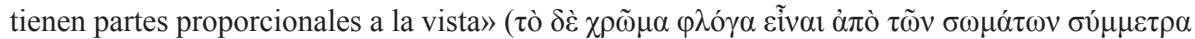

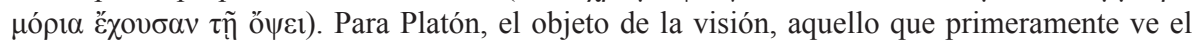
ojo, es el color, cuya constitución es fuego.

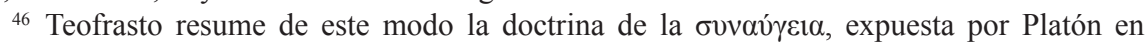
Timeo $67 \mathrm{~d}$ y $45 \mathrm{c}-\mathrm{d}$.

${ }^{47}$ Sobre la dificultad de interpretar el significado correcto de esta afirmación, cf. supra n. 22 . 
partir de la descripción desarrollada por Platón, puede deducirse que «el tener partes proporcionales a la vista tiene relación con la adaptación a los poros»

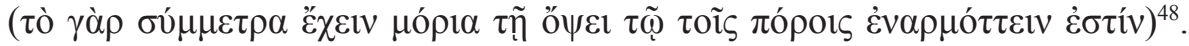
Tras esta breve explicación, Teofrasto califica tal doctrina de «absurda» (ǻo đov), así como también la identificación del color con la llama, dado que, a su juicio, con la llama solamente parece tener alguna semejanza el blanco, mientras que el negro parece lo contrario. Parece claro que el escueto desarrollo y la breve crítica desarrollada por Teofrasto a propósito de la doctrina platónica de la percepción visual se debe al hecho de su estrecha vinculación con la doctrina de Empédocles, vinculación, documentada, por otro lado, por el propio Platón ${ }^{49}$; así pues, una vez analizada críticamente la doctrina de Empédocles, Aristóteles y Teofrasto habrían desistido de entrar en detalle en lo que, a juicio de ambos, no sería sino una versión posterior y disminuida de la doctrina de Empédocles.

\section{IV}

Una vez refutadas las doctrinas ígneas del ojo desarrolladas por Alcmeón, Empédocles y Platón, Aristóteles ha superado un escollo fundamental en vista a desarrollar su propia doctrina de la percepción visual ${ }^{50}$; según esta, y de acuerdo con

${ }^{48}$ A juicio de Solana (2006, p. 34), «la observación [de Teofrasto] es exacta», y añade un claro indicio de la relación entre Empédocles y Platón en un fragmento del Timeo que, a propósito del olfato, afirma lo siguiente: «nuestros conductos relacionados con los olores son más estrechos respecto a las especies de tierra y agua, pero más anchos respecto a las de fuego y aire, por lo que nadie ha sentido nunca ninguna olfación de estos elementos» (66d). Tal como señala Solana acertadamente, «Platón no hace en este caso sino aplicar la teoría general de Empédocles de la adaptación entre los poros y los efluvios de los cuerpos». Una breve exposición de las semejanzas y diferencias entre Empédocles y Platón con respecto a la percepción visual se encuentra en Beare 1906, pp. 46-47.

${ }^{49}$ En el pasaje Men. 76a-d, Sócrates identifica el color con «emanaciones de las cosas»

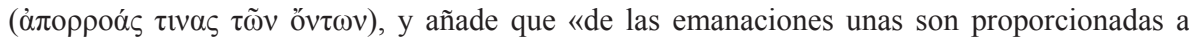

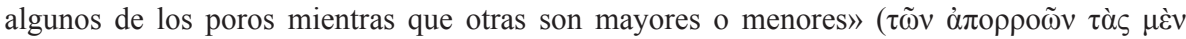

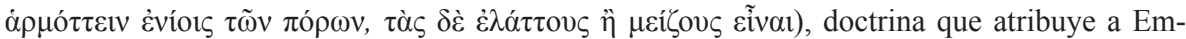
pédocles y a su discípulo Gorgias.

${ }^{50}$ Expuesta brevemente en De Sensu 2, 438 2 2-16; este breve resumen remite a la exposición más larga de de An. II 7. Finalmente, el Estagirita dedica De Sensu 3 al estudio de la génesis de los colores. Así pues, la doctrina aristotélica de la visión está principalmente expuesta en de An. II 7 y De Sensu 2, dedicados principalmente al estudio del objeto y del 
su doctrina general de la percepción, para que la visión sea posible siempre es necesario un medio diáfano, característica que comparten el aire y el agua, pero no el fuego. La exposición aristotélica de la visión está expuesta principalmente en $d e$ An. II 7. En este capítulo, Aristóteles primeramente identifica el objeto de la percepción visual con el color, al establecer que «todo color es un agente ca-

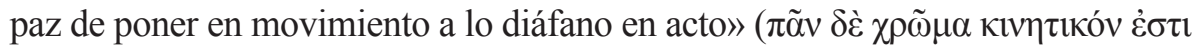
$\left.\tau \tilde{\omega} \kappa \alpha \tau^{\prime} \dot{\varepsilon} v \varepsilon \dot{\varepsilon} \rho \gamma \varepsilon \alpha_{\alpha} \delta 1 \alpha \varphi \alpha \nu \tilde{\omega} \varsigma\right)^{51}$. Aristóteles introduce en el proceso perceptivo

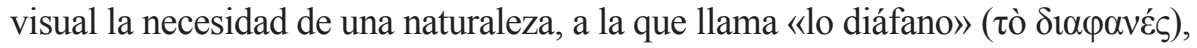
que identifica con aquello que posibilita la visión. Asimismo, Aristóteles llama la atención sobre la necesidad de la presencia de la luz a fin de hacer visible el

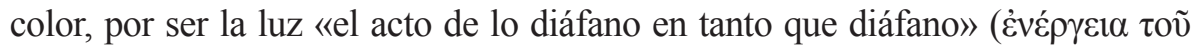

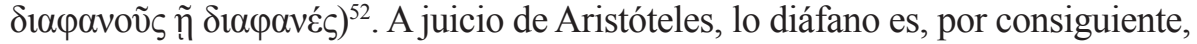
aquello que es visible, pero no en sí, sino en virtud de un color ajeno a él bajo la presencia de la luz. Lo diáfano se encuentra presente en numerosos cuerpos, y también en el aire y en el agua, y es precisamente en la medida en que en ellos se da la presencia de lo diáfano que el aire y el agua resultan medios adecuados para la visión. Según Aristóteles, en efecto, para que pueda producirse la visión, el órgano sensorial debe necesariamente ser afectado por algo; pero el órgano sensorial no puede de ningún modo ser afectado directamente por el color, de modo que es necesaria la presencia de un agente intermedio. ¿A qué se debe que el agente intermedio no pueda consistir en fuego? El argumento esgrimido por el Estagirita al respecto en de An. II 7 es el siguiente: porque el fuego se ve tanto bajo la presencia de la luz como en la oscuridad, de modo que lo diáfano se hace diáfano, precisamente, bajo su influjo ${ }^{53}$. Aristóteles resume brevemente en De Sensu 438b2-11 todo lo expuesto en de An. II 7, texto al que se remite. En efecto, el Estagirita expone nuevamente la necesidad de la presencia de la luz, y de «un medio entre lo que se ve y el ojo» (

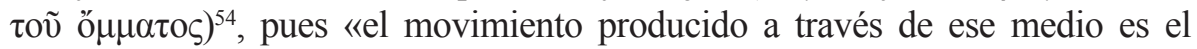

medio de la visión, y en De Sensu 2, dedicado principalmente al estudio del sensorio u órgano de la visión. Exposiciones generales de la doctrina aristotélica de la visión se encuentran en Beare 1906, pp. 56-92, y Cappelletti 1977. En cuanto a Teofrasto, este no aborda en De Sensibus ni la exposición de la doctrina aristotélica de la visión ni la suya propia, limitándose a exponer críticamente las doctrinas de los filósofos prearistotélicos.

${ }^{51}$ De An. II 7, 418 1 ; la definición de color se repite en $419^{\mathrm{a}} 13$ y en De Sensu 3, 439 18 -20.

$52418^{\mathrm{b}} 9-10$.

${ }_{53}$ Cf. de An. II 7, 418 $222-24$.

${ }^{54}$ De Sensu 2, $438^{\mathrm{b}} 4$. 


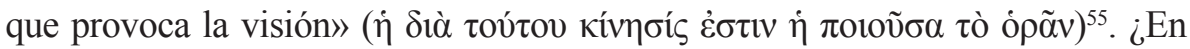
qué consiste ese medio? Tal como ya hemos visto, el medio no puede consistir en fuego, sino en agua; en palabras de Aristóteles, «el interior del ojo, lógica-

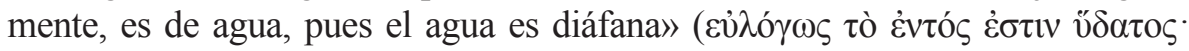

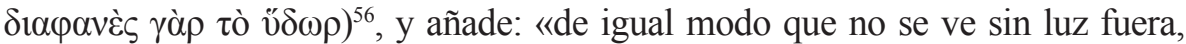
ocurre también dentro, por lo que es necesario que el interior sea diáfano» ( $\varepsilon_{\xi} \xi$

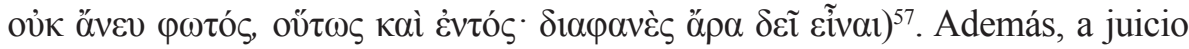
de Aristóteles, la parte sensitiva del alma no se encuentra en la superficie del ojo, sino que está dentro, de modo que «es necesario que el interior del ojo sea

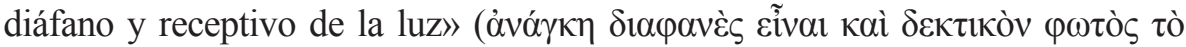

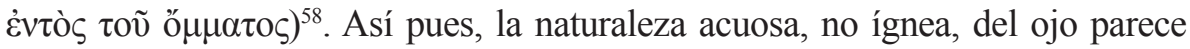
manifestarse como algo lógico y evidente, y constituye, junto con el aire diáfano del exterior, el medio que posibilita la visión. Ello se manifiesta además en una serie de experiencias cotidianas recogidas por el Estagirita ${ }^{59}$; así, cuando los ojos se descomponen, lo que parece fluir es agua; asimismo, en los animales de tipo sanguíneo, el blanco del ojo es grasiento y brillante, a fin de evitar que el agua del ojo se congele; y lo mismo se puede afirmar de las duras escamas de los animales sin sangre. Todo ello lleva a Aristóteles a concluir en el resumen final

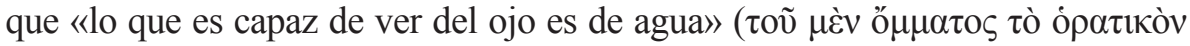

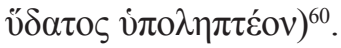

\section{BIBLIOGRAFÍA}

Alexander Aphrodisiensis 1901: In librum De sensu commentarium. Edición de

P. Wendland, en Commentaria in Aristotelem Graeca III 1, Berlin.

Baltussen, H. 1993: Theophrastus on theories of perception. Argument and Purpose in the De sensibus, Utrecht.

Baltussen, H. 2000: Theophrastus against the Presocratics and Plato, Leiden-Boston.

Beare, J. I. 1906: Greek theories of elementary cognition from Alcmeon to Aristotle, Oxford.

Bernabé, A. 1987: Aristóteles, Tratados breves de historia natural, Madrid.

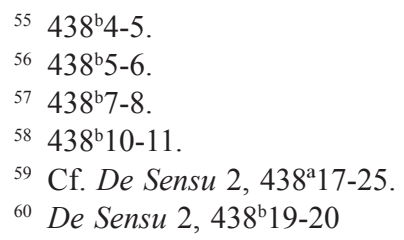


Bignone, E. 1916: Enpedocle, Turín.

Cappelletti, A. J. 1977: La teoría aristotélica de la visión, Caracas.

Diels, H. 1879: Doxographi Graeci, Berlín. [Existe traducción italiana sin índices ni prolegomena, a cargo de L. Torraca: I dossografi greci, Padua, 1961].

Diels, H. y Kranz, W. 1984 ${ }^{13}$ : Die Fragmente der Vorsokretiker, 3 vols., Berlín.

Kahn, Ch. 1960: Anaximander and the origins of Greek cosmology, Nueva York (reimp. 1994).

Lisi, F. 1992: Platón, DiálogosVI. Timeo, Madrid.

Long, A. A. 1966: "Thinking and Sense-Perception in Empedocles: Mysticism or Materialism», The Classical Quarterly 16, pp. 256-276.

McDiarmid 1959: «Plato in Theophrastus’ De Sensibus», Phronesis 4, pp. 59-70.

Mugnier, R. 1965: Aristote, Petits traités d'histoire naturelle, París.

O'Brien, D. 1970: «The Effect of a Simile: Empedocles' Theories of Seeing and Breathing», Journal of Hellenic Studies 90, pp. 140-179.

Osborne, H. 1968: "Colour concepts of the ancient Greeks», British Journal of Aesthetics 8, pp. 269-283.

Platnauer, M. 1921: «Greek colour perception», The Classical Quarterly 15, pp. 153162.

Rivaud, A. 1985: Platon, Oeuvres complètes X. Timée, París.

Sassi, M. M. 1978: Le teorie della percezione in Democrito, Florencia.

Solana, J. 2006 [1989ㄹ] : Teofrasto, Sobre las sensaciones, Anthropos, Barcelona.

Stratton, G. 1917: Theophrastus and the Greek physiology before Aristotle, LondresNueva York.

Struycken, P. 2003: «Colour mixtures according to Democritus and Plato», Mnemosyne LVI, pp. 273-305.

Themistius (Sophonias) 1903: In Parva Naturalia commentarium, ed. P. Wendland, en Commentaria in Aristotelem Graeca V 6, Berlín.

Verdenius, W. J. 1948: «Empedocles' Doctrine of sight», en VV. AA., Studia varia C. G. Vollgraff a discipulis oblata, Ámsterdam, pp. 155-164.

Watchler, J. 1896: De Alcmaeone Crotoniata, Leipzig.

Wrigth, M. R. 1981: Empedocles. The extant fragments, New Haven-Londres.

Fecha de recepción de la primera versión del artículo: 02/09/2010

Fecha de aceptación: 16/08/2011

Fecha de recepción de la versión definitiva: 07/01/2012 


\title{
Briáreo-Egeón: notas a Ilíada I 401-406*
}

\author{
Joan Pagès Cebrián
}

Universidad Autónoma de Barcelona

Joan.Pages.Cebrian@uab.cat

\section{Briareus-Aigaion: notes to Iliad I 401-406}

En el primer canto de la Ilíada (vv. 401-406) Homero hace una breve referencia al gigante Egeón, a quien los dioses llaman Briáreo. La identificación entre este personaje y el centímano Briáreo, hijo de Crono y Rea en la genealogía hesiódica, suscita algunos interrogantes. Un análisis detenido de las fuentes y algunos paralelos de la épica hitita sugieren la existencia de un mito antiguo de ascendencia anatolia vinculado a Egeón. El personaje fue posteriormente suplantado por Briáreo, el centímano hesiódico, en la épica panhelénica, hecho que provocó la marginación y posterior olvido de la leyenda antigua de Egeón.

Palabras clave: Egeón; Briáreo; mitología; mitografía; mitos anatolios; Ilíada; escolios a la Ilíada.
In the first book of the Iliad (vv. 401-406) Homer refers briefly to Aigaion the giant, whom the gods call Briareus. The identification of this character and the hundredhanded Briareus, son of Rhea and Cronos according to Hesiod's genealogy, raises some questions. A careful analysis of the sources and some parallel cases in Hittite epics suggest the existence of an ancient myth with an Anatolian origin related to Aigaion. This character was later supplanted by Briareus, the hesiodic hundredhanded, in Panhellenic epics. This fact gave rise to further marginalization and neglect of the ancient legend about Aigaion.

Keywords: Aigaion; Briareus; Mythology; Mythography; Anatolian Myth; Iliad; Scholia to the Iliad.

Según el comentarista Heráclito, autor de las Quaestiones Homericae ${ }^{1}$, Homero debería ser expulsado, ya no sólo de la república de Platón, sino de la

* Estudio realizado en el marco de los proyectos financiados 2009SGR1030 (Departament d'Universitats, Recerca i Societat de la Informació, Generalitat de Catalunya) y FFI201016301 (Ministerio de Ciencia e Innovación). Parte del trabajo se llevó a cabo en la Universidad de Brown (RI, Estados Unidos), durante una estancia de investigación financiada con una beca concedida por el Consortium for the Advanced Studies in Barcelona entre los meses de junio y agosto de 2010.

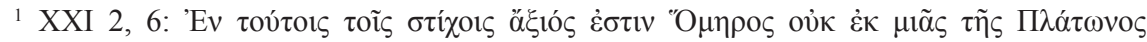

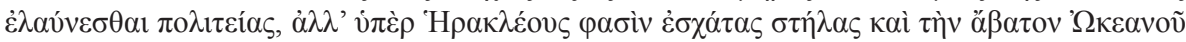
$\theta \alpha \dot{\lambda} \alpha \tau \tau \alpha \nu$, «Por estos versos Homero es merecedor de ser expulsado no solo de una (sic) de las repúblicas de Platón sino más allá de donde dicen que se hallan las remotas columnas de Héracles y las intransitables aguas del Océano». 
ecúmene entera, más allá de las columnas de Hércules, sólo por los versos 401-406 del canto primero de la Ilíada. A los ojos de un crítico racionalista como Heráclito el pasaje carece de la coherencia propia de un gran poeta. Semejante sensación provoca en el lector moderno. En estos versos Homero se refiere brevemente a un episodio conocido del anecdotario olímpico: Hera, Posidón y Atenea intentaron en cierta ocasión conspirar contra Zeus y atarlo para usurparle el poder ${ }^{2}$. Pero Tetis, para atemorizarlos, excarceló al centímano Briáreo, a quien los hombres llaman Egeón. El monstruo se sentó al lado de Zeus, exultante, y los conspiradores desistieron de su propósito. Facilitamos la transcripción del pasaje citado y la traducción de Crespo 1991:

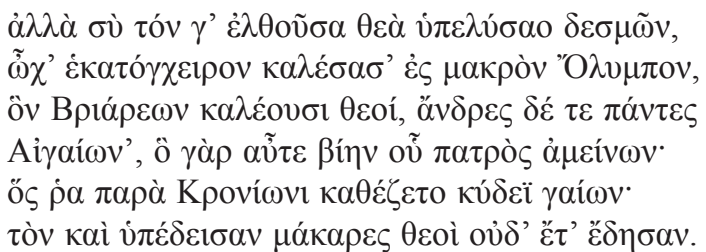

Mas tú, oh diosa, ascendiste y lo soltaste de las ataduras, llamando de inmediato al espacioso Olimpo al Centímano, a quien los dioses llaman Briáreo, y todos los hombres Egeón, porque él es a su vez más fuerte que su padre, quien se sentó al lado del Crónida, ufano de su gloria; los felices dioses sintieron miedo de él y ya no lo ataron.

El pasaje ha sido comentado ya desde los escolios antiguos. Suscita múltiples interrogantes. ¿Por qué los dioses olímpicos (excepto Zeus) se atemorizan ante un monstruo al cual una divinidad menor, Tetis, "saca a pasear» como a una mascota? Es obvio que esta perspectiva racionalista es la que suscitó el comentario de Heráclito. Pero hay más interrogantes: dice Homero que Briáreo-Egeón era más poderoso que su padre. Pero, ¿quién era su padre? Según la versión canónica, la de Hesíodo, era Urano, un dios primigenio. Pero, si fuera así, ¿por qué Homero nos habla de la superioridad de BriáreoEgeón respecto a Urano? ¿Qué relación tiene ello con el contexto?3.

2 Il. I 404-414.

${ }^{3}$ Para diversas propuestas de interpretación basadas en el léxico, la semántica y la etimología, así como la relación con el contexto, v. Hooker 1980, pp. 188-189; Fowler 1988, pp. 95-99. 
Veamos una panorámica sucinta de la tradición exegética del pasaje, y contrastémosla con el comentario irónico de Heráclito.

Aristonico nos transmite una emendatio del pasaje atribuida a Zenódoto:

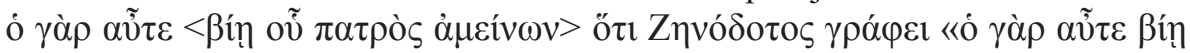

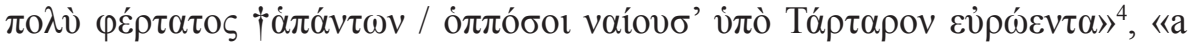
su vez, pues, <superior a su padre en fuerza>: que Zenódoto escribe "a su vez, pues, con mucho el más fuerte $(\dagger)$ de cuantos habitan bajo el sombrío Tártaro"». Vemos, pues, que los editores antiguos ya barajaban la posibilidad de que éste fuera un passus corruptus. Sin embargo, a nuestro entender la emendatio de Zenódoto, quien recurre a la tradición hesiódica ${ }^{5}$ para subsanar el deterioro del texto, es a todas luces excesiva.

La tradición escoliográfica falsamente atribuida a Dídimo comenta el pasaje desde una óptica puramente mitográfica:

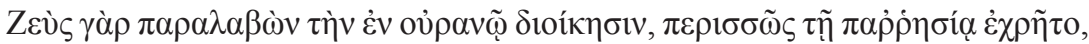

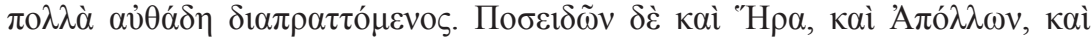

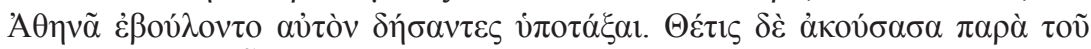

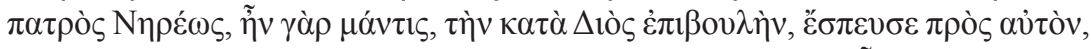

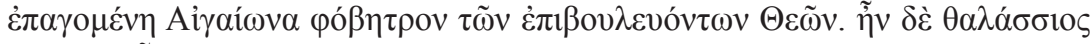

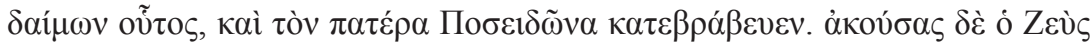

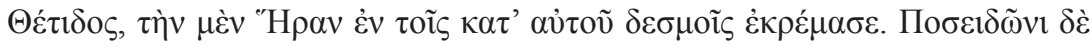

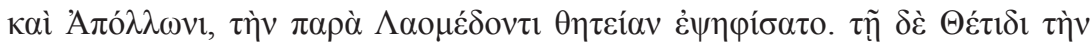

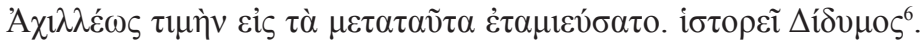

En efecto, Zeus, una vez hubo asumido el poder en el cielo, abusaba de su libertad de palabra y actuaba con suma arrogancia. Pero Posidón, Hera, Apolo y Atenea se proponían encadenarlo y someterlo. Tetis, habiéndose enterado por su padre Nereo, que era adivino, de la conspiración contra Zeus, se apresuró a socorrerle llevándose consigo a Egeón como espantajo contra los dioses conjurados. Era éste una divinidad marina que incluso privaba a su propio padre Posidón de su dignidad. Zeus, habiendo escuchado a Tetis, colgó a Hera con las mismas cadenas que habían sido destinadas a él. Para Posidón y Apolo decretó su servidumbre en la corte de Laomedonte. $\mathrm{Y}$ en reconocimiento a Tetis en lo sucesivo se encargó de honrar a Aquiles. Lo cuenta Dídimo.

${ }^{4}$ Sch. Er. Il. I 404a.

${ }^{5}$ Hes., Th. 729-731.

${ }^{6}$ Sch. D a Il. I 400 Heyne. 
Detengámonos en el comentario de este texto mitográfico. El objetivo del comentarista es, sin duda, ayudar al lector a comprender mejor el obiter dictum de Homero. Para ello nos da un resumen del episodio con más información de la que transmite el propio Homero y sin duda tributario del manual mitográfico conocido como Mythographus Homericus ${ }^{7}$. De su lectura sabemos que: 1) Apolo también estaba involucrado en la conspiración; 2) Tetis se percató de la confabulación gracias al poder oracular de su padre Nereo; 3) Tetis liberó a Egeón para servirse de su poder apotropaico (es un

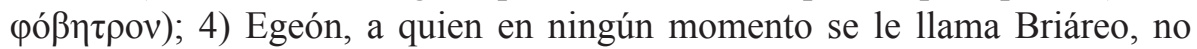
era un centímano sino un monstruo marino hijo de Posidón, al cual, en algún momento, mantenía desprovisto de su poder (si interpretamos correctamente

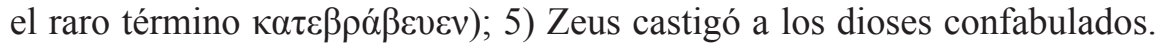

Centrémonos de nuevo en la figura de Briáreo/Egeón ${ }^{8}$. De la lectura del escolio parece deducirse que este Egeón tiene poco de centímano. ¿Por qué, pues, la doble denominación homérica? No cabe duda de que Homero está identificando a dos personajes originariamente diferentes. Sobre Briáreo, nos remitimos a Hesíodo, quien fija perfectamente la versión canónica del mito 9 . En cuanto a Egeón, las tradiciones discrepan. De hecho, bajo esta denominación, que no siempre es un nombre propio, encontramos en la tradición literaria personajes diferentes que pasamos a enumerar a continuación:

1. Centímano identificado con Briáreo ${ }^{10}$ que luchó contra los titanes como aliado de los dioses olímpicos ${ }^{11}$.

2. Monstruo precipitado al mar por Posidón y convertido en islote ${ }^{12}$. Si damos crédito al escoliasta de Apolonio, las fuentes últimas de esta versión serían la Heraclea de Cinetón y Demetrio de Escepsis.

7 Como atestigua el papiro de Oxirrinco 418, 23-32. Véase Montanari 1995, passim, Van Rossum-Steenbeek 1998, cap. 3, Cameron 2004, cap. 3.

${ }^{8}$ Véanse, en general, los artículos de Bernhard en Röscher 1884-1890, s. u. Aigaion y de Tümpel 1893. Por lo que respecta a la dicotomía homérica nombre divino/nombre humano, Haas 2006, pp. 313-314, advierte que en algunos textos religiosos hititas ya se da, y cita también paralelos en los Eddas nórdicos. El motivo parece ser, pues, indoeuropeo, y la coincidencia con los Eddas ya había sido notada por Calderón Felices 1982, p. 7, donde se ofrecen diversas interpretaciones de esta dualidad y uno de los ejemplos aducidos es precisamente el de Briáreo/Egeón (p. 9 ss.). V. también West 2007, pp. 160-162.

${ }^{9}$ Hes., Th. 149 ss., 817 ss.

${ }^{10} \mathrm{Il}$. 1. c.

${ }^{11}$ Titanomach. fr. 16 Bernabé; Nonn., D. XXXIX 285 ss.

12 A. R. I 1165 sch. ad loc. y Cono, FGH 26 F 2. 
3. Un monstruo marino que tenía su guarida en las costas de Eubea y provocaba maremotos que destruían las costas de las Cícladas ${ }^{13}$.

4. Rey de Caristo, en Eubea ${ }^{14}$.

5. Dios en cuyo honor se instituyeron unas competiciones atléticas en Efira (nombre antiguo de Corinto), posiblemente los Juegos Ístmicos ${ }^{15}$.

6. Uno de los cincuenta hijos de Licaón, rey de los $\operatorname{arcadios}^{16}$.

7. Héroe epónimo misio ${ }^{17}$.

8. Epíclesis de Posidón, por ser venerado en la ciudad de $\operatorname{Egas}^{18}$.

Esta multiplicidad no significa que nos hallemos ante una nómina casual de personajes con el mismo nombre. En primer lugar, ya Homero en la Ilíada, como hemos visto, identifica el 1 y el 2 . A su vez, el 2 y el 3 parecen ser el mismo monstruo marino con distinta ubicación geográfica. El escoliasta de Apolonio

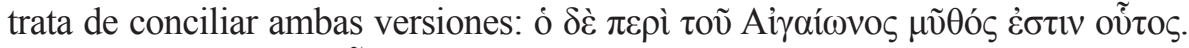

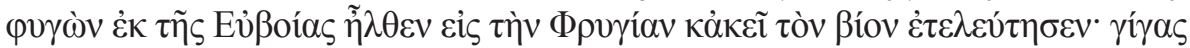
$\delta \dot{\varepsilon} \tilde{\eta} v$, «El mito de Egeón es este: huyendo de Eubea llegó a Frigia, donde acabó su vida. Era un gigante». Adviértase que se le denomina gigante, mientras que el escoliasta de Homero ${ }^{19}$ lo considera una divinidad marina ( $\left.\theta \alpha \lambda \alpha ́ \sigma \sigma 10 \varsigma \delta \alpha i ́ \mu \omega v\right)$. El 3 y el 4, en cambio, coinciden precisamente en su localización: Eubea. El 5 es un dios, posiblemente el propio Posidón denominado bajo una epíclesis, y con ello coincide con el 8. El 6 es el único que no parece tener nada que ver con los demás, y el 7 nos remite de nuevo al norte de Asia Menor, concretamente a Misia, con lo que se puede establecer un vínculo de relación con el 2. Según esta

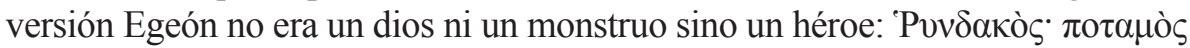

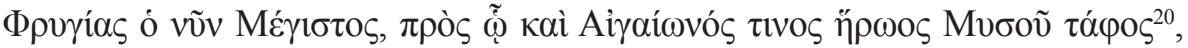
«Ríndaco: río de Frigia, el actual Megisto, cerca del cual se halla también la tumba de un tal Egeón, héroe misio».

Dejando el 6 aparte, presumiblemente nos hallamos ante variantes locales de un mismo mito: un personaje sobrehumano, un monstruo marino o quizás un dios

\footnotetext{
13 Arr., Bith. 35.

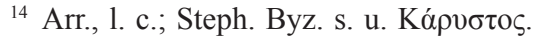

15 Call., SHell. 265; Plu. 2.612c-748d.

16 Apollod. III 8.1.

17 Sch. A. R., 1. c.

18 Sch. Lyc. 135.

19 L. c.

20 Sch. A. R., 1. c.
} 
primigenio, podría ser el dios del mar prehelénico ${ }^{21}$, antecesor de Posidón y suplantado por éste. En cuanto a la geografía, dos regiones se disputan los orígenes del mito: Eubea, concretamente Caristo, y la costa norte de Misia lindante con la Tróade, en la desembocadura del río Ríndaco. En cualquier caso, el mito en tanto que narración nos aleja de cualquier posibilidad de identificar a Egeón con Briáreo, es decir, con un centímano entendido a la manera canónica y panhelénica fijada por Hesíodo en su Teogonía. Intentemos, con la ayuda de los pocos testimonios con que contamos, reconstruir la anécdota narrativa del mito de Egeón.

Egeón, según la versión más antigua, la de Eumelo de Corinto ${ }^{22}$, era hijo del Mar y de la Tierra (de Ponto y Gea) ${ }^{23}$. Este poeta épico, en su Titanomaquia, hacía de Egeón un aliado de los titanes que luchó contra los olímpicos, con lo que la versión discrepa totalmente de la hesiodea ${ }^{24}$. Deducimos, pues, que el mito de Egeón al que se refieren los escoliastas de Homero y Apolonio no tiene relación con el Briáreo hesiódico. Nos hallamos ante una tradición diferente y, al parecer, irreconciliable.

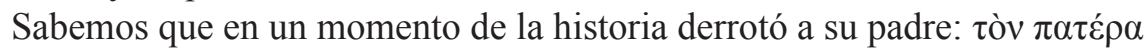

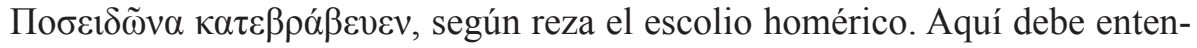
derse Posidón como una personificación del $\operatorname{mar}^{25}$. Nótese que a Egeón se le considera, según la versión a que nos remitamos, hijo de Posidón, de Ponto o del $\mathrm{Mar}^{26}$. Se afirma también lo contrario, que Egeón fue derrotado por

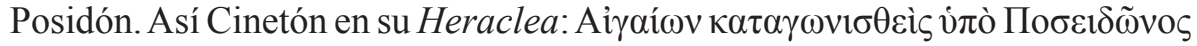

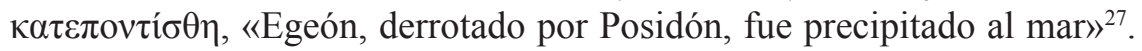

Podemos intentar ajustar estos motivos narrativos a una lógica mítica basándonos en paralelos griegos y anatolios. El mitema de las tres generacio-

21 V. Fowler 1988, p. 102.

${ }^{22}$ Véase al respecto West 2002, p. 110 ss., que ofrece un análisis sucinto de este mito y del lugar que ocupaba en la épica de Eumelo.

${ }^{23}$ Sch. A. R. cit. El escoliasta sin duda no pudo leer a Eumelo, cuyos textos ya no debían circular en época tardía, y lo cita indirectamente mediante el texto de Demetrio de Escepsis, que sin duda gozó de una transmisión más duradera.

24 V. Jacoby 1923, p. 500 (breve comentario al fragmento 2 de Conón, un segmento del escolio citado de Apolonio).

${ }^{25}$ Hay que tener en cuenta que en el análisis de estos mitos debemos fijarnos más en estereotipos simbólicos y patrones narrativos que en personajes y nombres concretos (Hardie 1983, p. 313).

${ }^{26} \Theta \alpha \lambda \alpha \dot{\sigma \sigma \sigma \eta \varsigma} \pi \alpha i ̃ \delta \alpha$ según el ditirambógrafo Ion, citado por el escoliasta de Apolonio (1.

c.). Respecto a la relación entre Egeón y el mar véase Fowler 1988, p. 99.

${ }^{27}$ Nuevamente en el citado escolio a Apolonio. 
nes sucesivas y de las luchas de la tercera para afianzar su poder constituye un patrón mítico-narrativo claramente establecido en textos literarios babilonios y anatolios ${ }^{28}$, así como en la Teogonía de Hesíodo ${ }^{29}$. Una vez la segunda generación ha sido derrotada y la tercera acaba de acceder al poder, se sucederán diversos intentos de involución para destronar a los dioses nuevos. El período de guerra será largo y dificultoso, y los dioses recién llegados temporalmente deberán esconderse o serán derrotados y dejados fuera de combate hasta que se produzca la ocasión del contraataque. Una vez vencidos los titanes, la Tierra, madre de éstos, engendrará nuevos monstruos como los Gigantes y Tifón. Todos ellos acabarán siendo aniquilados por el dios supremo con la ayuda de sus hermanos y aliados.

La lucha de Egeón contra su padre debe entenderse, de acuerdo con lo expuesto, en estos términos: el engendro de la tierra y el mar, nuevo hijo de las potencias primigenias relegadas de su hegemonía, vence al dios nuevo, pero sólo por un espacio de tiempo relativamente breve. Éste se rearmará y acabará derrotándolo definitivamente. Por eso la contradicción que hemos advertido no es tal: Egeón vence a su padre, el dios del mar (personificado ya sea en Ponto o en Posidón), pero a su vez será vencido posteriormente por Posidón ${ }^{30}$, el dios marino de la tercera generación. Así es restablecido, ya definitivamente, el orden en el universo.

El mito de Tifón se fundamenta en el mismo patrón mítico-narrativo, así como en su equivalente anatolio, el mito de Ullikummi ${ }^{31}$. En ambos el dios supremo es vencido y permanece fuera de combate hasta que se rearma, contraataca y derrota al adversario ${ }^{32}$.

${ }^{28}$ La sucesión de las tres generaciones y la consolidación del poder del dios supremo, perteneciente a la tercera, constituyen el patrón narrativo general subyacente al poema babilonio Enuma Eliš (v. Labat 1970, pp. 36-70) y al poema hitita El reinado en el cielo, versión anatolia de un mito hurrita (García Trabazo 2002, pp. 155-175). Véase Bernabé 1989, pp. 161-167; 174-177; Haas 2006, p. 132 ss.; López-Ruiz 2010, pp. 91-104, con paralelos cananeos comentados.

${ }^{29}$ Hes., Th. passim. La cuestión ha sido tratada en profundidad, entre otros, por Walcot 1966, pp. 1-54; Burkert 1992, p. 94 y West 1997, p. 280 ss.

${ }^{30}$ Del pasaje homérico comentado se deduce que en otras versiones no era Posidón sino Zeus quien lo derrota (v. infra).

${ }^{31}$ Güterbock 1951 y 1952; Walcot 1966, p. 7 ss.; Bernabé 1979, pp. 171-199; García Trabazo 2002 pp. 176-251; Bernabé 2004 passim; López-Ruiz 2010, pp. 91-94. Cf. Fontenrose $1980^{2}$, pp. $211-215$.

${ }^{32}$ Tal concatenación de los motivos míticos queda perfectamente recogida en la versión del mitógrafo Apolodoro (I 6.3); v. Fontenrose 1966 passim. 
Existe otro mito anatolio, conocido muy fragmentariamente, el mito de Hedammu $^{33}$, que presenta semejanzas sorprendentes con la historia de Egeón $\mathrm{y}$, a nuestro entender, arroja un poco de luz a la cuestión tan compleja de la correcta interpretación de este mito, así como al sentido del pasaje homérico comentado. Veamos, pues, los paralelos que se pueden establecer entre Hedammu y Egeón basándonos nuevamente en patrones mítico-narrativos ${ }^{34}$.

Hedammu es un monstruo marino hijo de Kumarbi ${ }^{35}$ (un dios de la segunda generación, como los Titanes ${ }^{36}$ ) que lucha contra los dioses nuevos (de la tercera generación, como los olímpicos). Eumelo de Corinto dice que Briáreo/Egeón fue aliado de los titanes, porque luchó contra los olímpicos (según la interpretatio Graeca.) Adviértase que Crono, el equivalente anatolio de Kumarbi, en Hesíodo y en Homero es un dios «bajo la tierra y el mar» ${ }^{37}$. El hecho de que Hedammu sea hijo de Kumarbi redunda en las connotaciones marinas: no cabe duda de que el Kumarbi de la versión hitita-hurrita de Hedammu es un dios marino, como el padre de Egeón. También a Egeón se le considera una divinidad ${ }^{38}$, hijo de Ponto o de Posidón, o sea, del mar si nos atenemos estrictamente a la simbología y función del mito ${ }^{39}$.

${ }^{33}$ Editado por Laroche 1965, pp. 169-176; Siegelová 1971 con traducción alemana y comentario. Versión en castellano en Bernabé (1979, pp. 157-170); lamentablemente García Trabazo no edita este texto en su excelente selección de textos hititas. Véase también Bernabé 2004, p. 134; Haas 2006, pp. 153-156.

34 Existen también paralelos cananeos; v. Pritchard $1969^{3}$, pp. 129-131; Fontenrose $1980^{2}$, pp. 129-138; Hardie 1983, p. 323; Olmo Lete 1995, pp. 91 y 106; Rutherford 2001, pp. 601602; López-Ruiz 2010, p. 156.

${ }_{35}$ V. fr. 1 y 2 Siegelová 1971, pp. 38-40 y comentarios de Bernabé 1979, p. 161. El mito de Hedammu forma parte del ciclo de Kumarbi en la mitología hurrita, conocida por sus versiones hititas conservadas fragmentariamente en las tablillas de Boğazköy. Restos de otro texto, denominado el Canto del Mar, escrito en hurrita y conservado en la tablilla KUB 45.63 parecen confirmar que el motivo de la lucha de Tešub contra el monstruo marino era una parte sustancial del mito de Kumarbi (Rutherford 2001, p. 602 ss.). La lucha se relaciona con el monte Hazzi, el Ká $\sigma \sigma i o v$ ópos de los autores griegos. Apollod. I 6.3 sitúa la lucha de Zeus contra Tifón precisamente en Cilicia (Bernabé 1989, p. 135). El mito es conocido también en textos ugaríticos, en que los dioses que luchan son Baal y Yam (West 2002, p. 111; Rutherford, 1. c.).

${ }^{36}$ Cf. Sch. a Il. II 783 Erbse, donde se dice que Tifón era hijo de Crono; v. Versnel 1987, p. 123.

${ }^{37}$ Il. XIV 202; v. Solmsen 1989, pp. 414-415; Versnel 1987, p. 124.

${ }_{38} \theta \alpha \lambda \alpha ́ \sigma \sigma t o \zeta ~ \delta \alpha i ́ \mu \omega v$ en el escolio citado de Homero.

39 Para la etimología de Airaí $\omega v$ y su posible relación con el mar en general, y el Egeo en particular, véase Hooker 1980; cf. Fowler 1988. 
La madre de Hedammu es Septarsuruhi, la hija del Gran Mar (equivalente en la mitología griega a Ponto u Océano ${ }^{40}$ ). El escoliasta de Homero afirma que es hijo de Posidón ${ }^{41}$, y Hesíodo convierte a Briáreo en yerno de Posidón ${ }^{42}$. Recordemos que, según Eumelo de Corinto, Egeón era hijo de Gea y Ponto.

En algún momento Hedammu combatió a los dioses nuevos, pues destruía las cosechas, el ganado y las labores de la humanidad ${ }^{43}$, desafiando a Tešub, el dios de la tempestad anatolio, y amenazando con destruir el equilibrio del cosmos sólo garantizado por los dioses nuevos. Egeón también desafió a los dioses nuevos, como parece deducirse de las palabras del escoliasta de Ho-

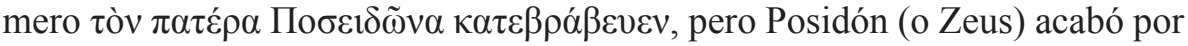
derrotarlo arrojándole una enorme mole de tierra y sepultándolo bajo el mar. El final del mito de Hedammu nos es desconocido por el estado fragmentario del texto, pero si nos ceñimos al patrón narrativo compartido, sin duda debía ser equivalente.

Previamente a su derrota definitiva, Hedammu es seducido por $\operatorname{Ištar}^{44}$, la diosa hermana de Tešub en las versiones hititas del mito hurrita ${ }^{45}$, con concomitancias funcionales, estructurales y simbólicas con la cipro-fenicia Astarté, la cananea Anat y la sumeria Inanna, así como la griega Afrodita ${ }^{46}$. He aquí el fragmento (Hedammu, fr. 16, líneas 11-16 Siegelová 1971, pp. 60-61):

${ }^{40}$ Cf. Apollod. III 8.1, donde se dice que Egeón es hijo de Melibea, hija de Océano. El paralelo es asombrosamente significativo.

${ }^{41}$ El dios designa aquí el medio o el elemento, como cuando Homero se refiere al fuego bajo el nombre de Hefesto, o a la guerra bajo el de Ares. Advertimos nuevamente el valor alegórico de las divinidades.

${ }^{42}$ Th. 817 ss.

${ }^{43}$ El relato nos presenta a un monstruo de gran voracidad que sale del mar y engulle todo cuanto encuentra a su alcance; v. fr. 2 y 3 Siegelová 1971, pp. 40-43 y comentarios de Bernabé 1979, p. 162.

${ }^{44}$ V. Fontenrose $1980^{2}$, p. 259. Uno de los episodios mejor conservados del poema de Hedammu es el que describe la toilette de Ištar previa al episodio de la seducción; v. De Vries 1967 pp. 49-51; Bernabé 2004 p. 134. Es inevitable pensar en otros paralelos, como el de la toilette de Hera en el canto XIV de la Ilíada (170-186), o bien el episodio de Enkidu y la cortesana en el poema babilonio de Gilgameš (v. Fontenrose $1980^{2}$, pp. 175, 215). Sin duda estos motivos están interrelacionados. Rutherford advierte sobre un episodio muy parecido protagonizado por Astarté y testimoniado en un texto egipcio (Pritchard 1969³, p. 17; Rutherford 2001, p. 602). Cf. Canto de Ullikummi, tablilla II, II 5'-14' (García Trabazo 2002, pp. 216-217); v. nota 49.

${ }^{45}$ El nombre hitita de este dios es Tarhunt(a)/Tarhunna, el dios de la tempestad indoeuropeo. V. West 2007, p. 247.

${ }^{46}$ Burkert 1992, pp. 96-100; West 1997, p. 408. 
[DIŠTAR-i(̌s A-NA MUŠhé-dam-mu)] me-mi-iš-ki-u-an da-iš ša-ra-a-kán

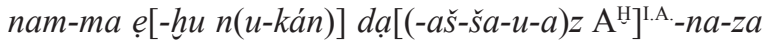

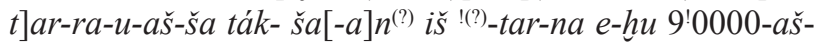
kán ${ }^{(?)}$ har [- $] \times[0] \times$

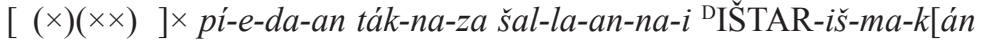
$A-N A$ MUšhé-dam-mu]

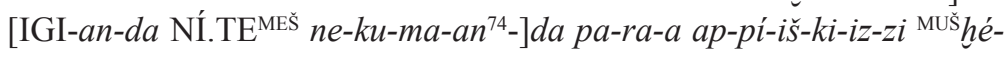
dam-mu-uš [

]LÚ-na-tar par-ra-a ua-at-ku-uš-ki-iz-zi nu LÚ-na-ta[r ] $\times \times{ }^{\mathrm{HI}} \mathrm{A75}$ ar-ma-ah-hi-iš-ki-iz-zi

Istar comenzó a decirle a Hedammu:

- iSube de nuevo!

¡Ven desde las poderosas aguas,

... con el vientre por la mitad!

Noventa mil ... saca desde la tierra al lugar,

pero Istar frente a Hedammu

levantó sus miembros desnudos.

Hedammu la vio

y su virilidad se excitó.

Su virilidad fluyó dentro de ella.

Y la dejó embarazada (trad. A. Bernabé 1979, p. 169).

Las connotaciones marinas de estas divinidades son perfectamente conocidas. En el mito de Egeón es Tetis, también una diosa marina, la que puede apaciguar al monstruo. Este es, a mi modo de ver, el paralelismo más significativo y el que confiere un sentido al pasaje homérico. Nuestro conocimiento deficiente de los mitos de Egeón y Hedammu puede repararse parcialmente comparándolos, como estamos viendo. Sin duda Tetis cumple en la historia de Egeón el papel de Ištar en el mito de Hedammu. Debemos entender, pues, que Tetis, en el pasaje homérico, puede liberar al monstruo sin temor gracias a sus dotes de seducción, y podemos incluso inferir que en la versión más completa tal vez Tetis sedujera a Egeón para que el dios supremo (Zeus o Posidón) pudiera derrotarlo, análogamente a lo que se narra de Hedammu con Ištar. Tetis, diosa marina con evidentes connotaciones eróticas, pretendida en su día tanto por Zeus como por Posidón ${ }^{47}$, es la única divinidad que puede excarcelar al monstruo sin que éste constituya de nuevo una amenaza contra

${ }^{47}$ Pi., I. VIII 27. 
el orden cósmico, y puede así ser utilizado por su poder apotropaico en una teomaquia.

Es muy probable que el dios que derrotara a Egeón fuera Zeus según algunas versiones y Posidón según otras. En el mito que subyace al pasaje homérico comentado era sin duda Zeus, ya que Posidón es uno de los dioses confabulados que se atemorizan al ver al monstruo. La versión es irreconciliable con la de Cinetón, quien nos dice que Egeón fue derrotado por Posidón ${ }^{48}$.

En la versión hurrita del mito de Hedammu, Tešub se consolida en el trono y reafirma su poder indiscutible, como ocurre con el mito de Ullikum$\mathrm{mi}^{49}$, y en Grecia el de Tifón. Los paralelismos con Tifón son evidentes, como ya hemos advertido. La estructura mítica y narrativa es muy próxima. Egeón (y suponemos que también Hedammu) acabarán precipitados al mar bajo una mole de tierra, motivo que confiere al mito un carácter etiológico. Otros gigantes míticos yacen también bajo promontorios, islas y montañas a los cuales dan nombre.

Vemos, pues, que la estructura y función de los mitos de Egeón y Hedammu son plenamente equiparables, y en el plano de la simbología y etiología podemos incluso ampliar el ámbito de la comparación y establecer paralelismos con otros mitos de lucha entre los dioses supremos, garantes del orden y la justicia, y las fuerzas primigenias descontroladas, que amenazan con desatarse en el momento menos esperado.

48 V. supra.

49 El mito de Ullikummi y el de Hedammu son equiparables por su estructura y simbología. Algunos especialistas consideran el mito de Hedammu una expansión o variante del de Ullikummi, incluso que los fragmentos del poema de Hedammu forman parte del más extenso de Ullikummi, del cual no eran más que un excurso (Haas 2007, p. 348). Pero sin duda sus relatos hacen de ellos dos personajes diferentes. Ullikummi es una montaña de diorita o basalto, mientras que Hedammu es un monstruo serpentino. Laroche edita los fragmentos de uno y otro mito en textos separados, considerándolos parte de poemas diferentes; v. también Haas 2006, pp. 156-160. Véase la edición del Canto de Ullikummi en Güterbock 1951 y 1952 passim (edición crítica con traducción inglesa), Pecchioli Daddi y Polvani 1990, pp. 142-162 (introducción y traducción italiana anotada), Haas 1994, pp. 88-96 (con traducción parcial y comentario), Hoffner 1998, pp. 55-65 (introducción y traducción inglesa), García Trabazo 2002, pp. 176-251 (introducción y traducción castellana anotada); para Hedammu, v. Siegelová 1971 (edición crítica con traducción alemana), Bernabé 1979, pp. 157-170 (introducción y traducción castellana), Pecchioli Daddi y Polvani 1990, pp. 131-142 (introducción y traducción italiana anotada), Hoffner 1998, pp. 50-55 (introducción y traducción inglesa). 
La historia del monstruo Egeón, posiblemente originada en Eubea, llegó a las costas de la Tróade en un momento que no podemos precisar. Allí se contaminó con motivos orientales, como el de la diosa seductora que ayuda al dios supremo a vencer al monstruo ${ }^{50}$. Las comunidades de la Tróade en época arcaica eran mixtas. En ellas los colonos griegos convivían con la población autóctona anatolia, quizás luvita, y posiblemente con otros contingentes de población sobrevenidos, tracios, frigios y misios ${ }^{51}$. Los mitos de las diferentes etnias interactuaban y los aedos, creadores de tradición épica fundamentada en el acerbo tradicional de las leyendas locales, no dudaban en componer versiones que amalgamaban motivos de diversa procedencia. El influjo oriental en el mito y la epopeya griega son motivo de estudio continuado desde hace ya varias décadas, y muchos paralelismos han sido ya establecidos y demostrados.

Podemos, pues, postular un sincretismo mítico entre las figuras de Egeón y Hedammu (o una variante local equivalente). La figura de Tetis fue sin duda clave para establecer esta analogía: el mito de Egeón es el único mito griego que conozcamos en el que el dios supremo recurre a la figura de una divinidad femenina que hace uso de su poder de seducción para neutralizar la fuerza del monstruo, y ello se debe a la influencia anatolia de mitos como el de Hedammu. Contrariamente, en otros mitos similares, como el del anatolio Ullikummi y el del griego Tifón, el dios supremo es ayudado por una divinidad masculina que recurre a la astucia.

Los datos proporcionados por los mitógrafos y escoliastas griegos parecen fusionar tres temas míticos relacionados con las luchas previas a la consolidación del poder de la tercera generación divina, la que ostentará la hegemonía definitiva. El primero es el de la Titanomaquia. En la versión de Eumelo de Corinto, Egeón es aliado de los Titanes y lucha contra los olím-

${ }^{50}$ Cabe contemplar también la posibilidad de que en la primitiva versión euboica la figura de Tetis ya desempeñara un papel primordial en el relato. Esta hipótesis adquiere más fuerza si se admite el origen anatolio, probablemente luvita, del sustrato prehelénico que se reconoce en la toponimia de gran parte del territorio griego, concretamente los nombres con

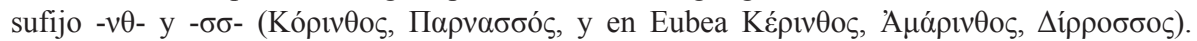
Véase al respecto Finkelberg 2005, p. 42 ss. (con mapas y copiosa bibliografía sobre tan vieja cuestión). Desde esta óptica las influencias anatolias no serían debidas a intercambios comerciales y zonas de contacto en la costa minorasiática sino que se remontarían al sustrato prehelénico en suelo griego.

51 V. Bryce 2006, p. 127 ss. 
picos. El segundo es el de la Gigantomaquia ${ }^{52}$, ya que Egeón aparece como un gigante engendrado por Gea y Ponto que pone en peligro a los dioses nuevos. El tercero es el de la Tifonomaquia, del cual toma el motivo de la derrota del monstruo aplastado bajo una mole de tierra que será su túmulo en medio del marr $^{53}$, referente de navegantes y con claras connotaciones etiológicas. Así, para Apolonio de Rodas ${ }^{54}$ Egeón está sepultado bajo el

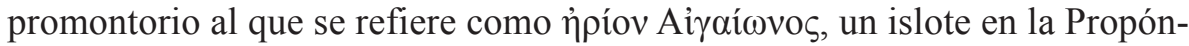
tide cerca de la desembocadura del antiguo Ríndaco ${ }^{55}$. También se reconoce en algunos montes o incluso en la isla de Sicilia la mole de tierra que aplastó a Tifón. Otros gigantes están atrapados bajo otras regiones, así, por ejemplo, en la Gigantomaquia narrada en la Biblioteca de pseudo-Apolodoro, Posidón arranca una parte de la isla de Cos y la arroja sobre Polibotes, quien quedará sepultado bajo la nueva isla de Nisiros, y Atenea hará otro tanto con Encélado y Sicilia ${ }^{56}$.

En resumen, pues, podemos afirmar que la restitución del mito de Egeón es, a la luz de las fuentes, tarea casi imposible, sobre todo si se parte de la idea preconcebida de que existió una única versión primigenia. El mito es la suma de todas sus variantes, y aquí hemos intentado una restitución en líneas generales, atendiendo más a estereotipos mítico-narrativos que a personajes y motivos perfectamente perfilados ${ }^{57}$.

Homero y Hesíodo, cada uno según su criterio compositivo y de acuerdo con sus objetivos literarios programáticos, intentaron integrar el mito de Egeón en sus respectivas cosmologías. Homero lo identificó con Briáreo, personaje ya encajado en las genealogías divinas gracias a la complejísima labor genealógica subyacente a la Teogonía de Hesíodo. Ello supuso una alteración radical del mito, ya que Egeón, que había luchado contra los dioses olímpicos en la Titanomaquia, al ser identificado con Briáreo se convirtió en aliado de éstos. Para Homero, Egeón-Briáreo será uno de tantos gigantes derrotados y aprisionados bajo tierra a quien el dios supremo puede utilizar como $\varphi$ ß́ $\eta \tau \rho o v$, como se ve en el episodio narrado en el escolio.

${ }^{52}$ La confusión entre los ciclos de la Titanomaquia y la Gigantomaquia en el arte y la literatura arcaicos ya fue advertida por Vian 1952, p. 169 ss.

${ }^{53}$ Motivo también presente en la Gigantomaquia (v. infra).

${ }^{54}$ I 1124, locus comentado por el escoliasta, como hemos visto.

55 V. Delage 1930, pp. 114-115.

${ }^{56}$ Apollod. I 6.1; v. Hardie 1983, p. 323.

${ }^{57} \mathrm{~V}$. nota 25. 
Por su parte, Hesíodo ${ }^{58}$ nos dice que Posidón eligió a Briáreo para yerno, casándolo con su hija Cimopolea, en agradecimiento por haber luchado a favor de los dioses olímpicos en la Titanomaquia. Tanto Homero como Hesíodo ponen a Briáreo en relación con el mar e identifican al centímano con el legendario Egeón ${ }^{59}$ con el propósito de incorporar estas antiguas leyendas locales de monstruos marinos a la versión canónica de los grandes mitos panhelénicos. La legitimidad que confieren las versiones homéricas y hesiódicas a los mitos revierte en la marginación y olvido de las discrepancias locales ${ }^{60}$. La épica de Eumelo ${ }^{61}$ y Cinetón será olvidada, por no encajar en los parámetros homéricos y hesiódicos. Pero esas versiones marginales (y marginadas) aflorarán de nuevo, sobre todo por el interés que suscitaron en los poetas helenísticos como Apolonio de Rodas, siempre atento a la etiología antigua redescubierta al paso de sus Argonautas y situada sobre los mapas de navegación. Los escoliastas nos han transmitido noticias recabadas en los textos de esos poetas, así como de historiadores locales como Demetrio de Escepsis.

¿Por qué Homero rememora el mito de Egeón en el pasaje objeto de este análisis? Es evidente que los primeros oyentes de la épica homérica, allá por el siglo VIII a. C., conocían perfectamente la historia de Egeón, pues sin este conocimiento la referencia homérica no tiene ningún sentido. Los aedos y rapsodas recitaban para un público con el cual establecían una relación de complicidad. Ello les permitía rememorar otros mitos mediante breves referencias y alusiones, a veces excursos más prolongados, que sin duda complacían a un auditorio ansioso de nuevas historias pero también nostálgico y deseoso de recordar los viejos mitos. Todas esas historias antiguas debían ser resituadas en el universo mítico que se estaba sistematizando, en el cual cada leyenda, cada tradición local, había de integrarse o de lo contrario era condenada al olvido. $\mathrm{Y}$ eso es precisamente lo que hace Homero con Egeón al identificarlo con

${ }^{58}$ Th. 811 ss., en un pasaje tal vez interpolado según criterio de algunos editores. Homero y Hesíodo se basan en tradiciones diferentes, a pesar de que tienden a aproximarse; véase al respecto Solmsen 1989, passim, y especialmente sus conclusiones en p. 422.

${ }^{59}$ Homero explícitamente. Hesíodo no usa en ningún momento el nombre de Egeón.

${ }^{60}$ V. Nagy 1990, p. 37 ss.

${ }^{61}$ West 2002, passim, postula la existencia de un ciclo épico arcaico corintio. El nombre de Eumelo sería un denominativo genérico, como el de Homero para la épica del ciclo troyano. Un reflejo de la tradición deudora de Eumelo en Verg., Aen. X 565-8 (v. West 2002, p. 111, especialmente nota 13). 
Briáreo. Dicha identificación provocó el olvido de la auténtica historia de Egeón, que afloraría a duras penas siglos más tarde en los escolios.

\section{BIBLIOGRAFÍA}

Bernabé, A. 1979: Textos literarios hetitas, Madrid.

Bernabé, A. 1989: «Generaciones de dioses y sucesión interrumpida. El mito hitita de Kumarbi, la Teogonía de Hesíodo y el Papiro de Derveni», Aula Orientalis 7, pp. 159-179.

Bernabé, A. 2004: «La lucha contra el dragón en Anatolia y en Grecia», Huelva arqueológica 19, pp. 129-145.

Bryce, T. 2006: The Trojans and their neighbours, Londres-Nueva York.

Buffière, F. (ed.) 1962: Héraclite. Allégories d'Homère, París, Les Belles Lettres.

Burkert, W. 1992: The orientalizing revolution. Near Eastern influence on Greek Literature in Early Archaic Greece, Cambridge (MA)-Londres.

Calderón Felices, J. 1982: «Lengua de los dioses, lengua de los hombres», Faventia 1.4, pp. 5-33.

Cameron, A. 2004: Greek Mythography in the Roman World, Oxford.

Crespo, E. 1991: Homero, Ilíada. Traducción, prólogo y notas, Madrid.

Delage, E. 1930: La Géographie dans les Argonautiques d'Apollonios de Rhodes, Burdeos-París.

De Vries, B. 1967: The style of Hittite Epic and Mythology, Diss. Brandeis.

Erbse H. (ed.) 1969: Scholia Graeca in Homeri Iliadem (scholia vetera), vol. 1, Berlín.

Finkelberg, M. 2005: Greeks and pre-Greeks. Aegean prehistory and ancient heroic tradition, Cambridge.

Fontenrose, J. 1966: «Typhon among the Arimoi», en Wallach, L. (ed.), The Classical Tradition. Literary and Historical Studies in honour of Harry Caplan, IthacaNueva York, pp. 64-82.

Fontenrose, J. $1980^{2}$ (1959): Python. A Study of Delphic Myth and Its Origins, Berkeley-Los Ángeles-Londres.

Fowler, R. L. 1988: «AIГ- in early Greek language and Myth», Phoenix 42.2, pp. 95113.

García Trabazo, J. V. 2002: Textos religiosos hititas, Madrid.

Grenfell, B. y Hunt, A. (eds.) 1903: The Oxyrhynchus papyri 3, Londres.

Güterbock, H. G. 1951: «The song of Ullikummi. Revised Text of the Hittite Version of a Hurrian Myth», Journal of Cuneiform Studies 5, pp. 135-161.

Güterbock, H. G. 1952: «The song of Ullikummi. Revised Text of the Hittite Version of a Hurrian Myth (continued)», Journal of Cuneiform Studies 6, pp. 8-42.

Haas, V. 1994: Geschichte der hethitischen Religion, Leiden-Nueva York-Colonia. 
Haas, V. 2006: Die hethitische Literatur. Texte, Stilistik, Motive, Berlín-Nueva York. Haas, V. 2007: «Beispiele für intertextualität im hethitischen rituellen Schrifttum», en Goddek, D. y Zorman, M. (eds.), Tabularia Hethaeorum. Hethitologische Beiträge, Wiesbaden.

Hardie, P. R. 1983: «Some themes from Gigantomachy in the Aeneid», Hermes 111, pp. 311-326.

Heyne, C. G. (ed.) 1834: Homeri Ilias (cum Scholiis), Oxford.

Hoffner, H. A. (ed.) 1998: Hittite Myths, Atlanta.

Hooker, J. T. 1980: «AIГAISN in Achilles' plea to Thetis», JHS 100, pp. 188-189.

Hubert, C. (ed.) 1938: Plutarchi Moralia, vol. 4, Leipzig (reimpr. 1971).

Jacoby, F. (ed.) 1923: Die Fragmente der griechischen Historiker. Erster Teil: Genealogie und Mythographie, Berlín.

Labat, R. et al. (eds.) 1970: Les religions du Proche-Orient asiatique. Textes babyloniens, ougaritiques, hittites, présentés et traduits par R. Labat, A. Caquot, M. Sznycer, M. Vieyra, París.

Laroche, E. 1965: Textes mythologiques Hittites en transcription. Première partie: Mythologie anatolienne, París.

Lentz, A. (ed.) 1867: Grammatici Graeci, vol. 3.1, Leipzig (reimpr. 1965).

Lloyd-Jones, H. y Parsons, P. 1983: Supplementum Hellenisticum, Berlín.

López-Ruiz, C. 2010: When the Gods Were Born. Greek Cosmogonies and the Near East. Cambridge (MA)-Londres.

Montanari, F. 1995: «The Mythographus Homericus», en Abbenes, J. G. J. S., Slings, S. R. y Sluiter, I. (eds.), Greek Literary Theory after Aristotle: a collection of papers in honor of D. M. Schenkeveld, Ámsterdam, pp. 113-125.

Nagy, G. 1990: Greek Mythology and Poetics, Ithaca-Londres.

Olmo Lete, G. 1995: «La religion de Siria en el II milenio a. C. (1500-1200)», en Olmo Lete G. (ed.), Mitología y religión del Oriente Antiguo II/2, Sabadell, pp. 45-222.

Pecchioli Daddi, F. y Polvani, A. M. (eds.) 1990: La mitologia ittita, Brescia.

Pritchard, J. B. (ed.) 19693: Ancient Near Eastern Texts Relating to the Old Testament, Princeton.

Roscher, W. H. 1884-1890: Ausführliches Lexikon der griechischen und römischen Mythologie I, Leipzig.

Rutherford, I. 2001: «The song of the Sea ( $\breve{S} A$ A AB.BA SìR). Thoughts on KBU 45.63», en Wilhelm, G. (ed.), Studien zu den Boğazköy-Texten 45. Akten des IV. Internationalen Kongresses für Hethitologie, Mainz, pp. 599-609.

Scheer, E. (ed.) 1958: Lycophronis Alexandra, vol. 2, Berlín.

Siegelová, J. 1971: Appu-Märchen und Hedammu-Mythus. Studien zu den BogazköyTexten 14, Wiesbaden.

Solmsen, F. 1989: «The two Near Eastern sources of Hesiod», Hermes 117, pp. 413422. 
Tümpel, K. 1893: «Aigaion», en RE I 1, Stuttgart, pp. 945-947.

Van Rossum-Steenbeek, M. 1998: Greek Reader's Digest? Studies on a selection of Greek subliterary papyri, Leiden-Nueva York-Colonia.

Versnel, H. S. 1987: «Greek Myth and Ritual: the case of Kronos», en Bremmer, J.

(ed.), Interpretations of Greek Mythology, Londres, pp. 121-152.

Vian, F. 1952: La guerre des Géants: le mythe avant l'époque hellénistique, París.

Walcot, P. 1966: Hesiod and the Near East, Cardiff.

West, M. 1997: The East face of Helicon. West Asiatic Elements in Greek Poetry and Myth, Oxford.

West, M. 2002: «Eumelos: a Corinthian epic cycle?», JHS 122, pp. 109-133.

West, M. 2007: Indo-European Poetry and Myth, Oxford.

Fecha de recepción de la primera versión del artículo: 11/11/2010

Fecha de aceptación: 15/09/2011

Fecha de recepción de la versión definitiva: 27/02/2012 